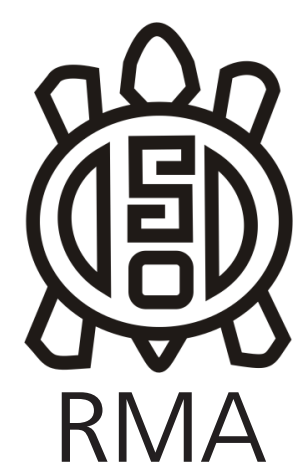

Antropología Social

\section{Lo etnográfico y la génesis de una matriz disciplinaria en la antropología social argentina}

\author{
The ethnographic and the genesis of a disciplinary matrix in Argentine \\ social anthropology
}

Sergio E. Visacovsky*

${ }^{*}$ Centro de Investigaciones Sociales (CIS-IDES/CONICET). E-mail: sergio.visacovsky@ides.org.ar

\begin{abstract}
Resumen
En este artículo trato el desarrollo de la antropología en la Argentina desde el retorno democrático a inicios de la década de 1980 hasta los inicios del corriente siglo. Mi pretensión es analizar cómo lo etnográfico llegó a ser una matriz disciplinaria. Como mostraré, lo etnográfico devino en el modo aceptado y normal de producción de conocimiento antropológico en la Argentina en los albores del presente siglo. Por un lado, centro mi atención en la enseñanza universitaria de la investigación en antropología y el liderazgo de figuras claves, como Rosana Guber. Por otro, muestro la influencia crucial de la antropología brasileña para la transformación de la matriz disciplinar, lo cual permitió la recuperación y legitimación de desarrollos locales precedentes. Finalmente, destaco la importancia de los posgrados para la cristalización de los proyectos disciplinares centrados en lo etnográfico, los cuales rompieron el monopolio de las definiciones legítimas que conservaban las carreras de antropología.
\end{abstract}

Palabras calve: Etnografía; Matriz disciplinaria; Antropología social; Argentina; Brasil.

\begin{abstract}
In this article I deal with the development of anthropology in Argentina since the democratic return at the beginning of the 1980s to the beginning of the current century. My intention is to analyze how the ethnographic became a disciplinary matrix. As I will show, the ethnographic became the accepted and normal mode of anthropological knowledge production in Argentina at the dawn of the new century. On the one hand, I focus my attention on the university teaching of anthropology research and the leadership of key figures, such as Rosana Guber. On the other hand, I show the crucial influence of Brazilian anthropology for the transformation of the disciplinary matrix, which allowed the recovery and legitimization of previous local developments. Finally, I highlight the importance of postgraduate courses for the materialization of disciplinary projects focused on ethnography, which broke the monopoly of legitimate definitions that anthropology careers conserved.
\end{abstract}

Keywords: Ethnography; Disciplinary matrix; Social Anthropology; Argentina; Brazil.

En 2014 participé junto a otros colegas ${ }^{1}$ como jurado de los Premios Nacionales de Ensayo en el rubro "Ensayo Antropológico", una distinción que concede el Ministerio de Cultura de la Nación. En esa ocasión, concursaron los autores de libros publicados entre 2010 y 2013. De los 93 libros recibidos (entre los cuales se mezclaban la arqueología, la bioantropología, la paleoantropología, la lingüística, la historiografía y hasta la poesía), 22 fueron textos que catalogamos como "etnográficos". Si bien esta clasificación dependía de ciertos criterios establecidos por el jurado, muchos de los libros apelaban a la mencionada categoría para identificar el carácter del texto, los métodos y técnicas empleados o el enfoque analítico.

Los trabajos presentados mostraban de modo notorio

1 Rosana Guber, Roberto Abinzano, Hugo Trinchero y Pablo Semán. cómo desde el inicio del corriente siglo se habían multiplicado los temas de investigación, cómo nuevas poblaciones, regiones y escenarios habían sido transformados en nuevos objetos de atención, de modo tal que si aún quedaban aspectos de la realidad que no hubiesen sido convertidos en focos de una indagación que recibiera el nombre de "etnográfica", era de esperar que en los próximos años fuesen objeto de estudio con todo derecho. ${ }^{2}$ Pero había algo más: lo que ponían de manifiesto tanto las operaciones de ordenamiento del

2 Los temas de los libros que concursaron incluían: la memoria colectiva del terrorismo de Estado, las políticas públicas, los movimientos de desocupados, la política local, la segregación urbana, la vida de los migrantes, los pueblos originarios, la institución escolar y la educación, los militares y el régimen democrático, la economía cotidiana de los sectores subalternos, el mundo de los diseñadores como emprendedores, la violencia en el fútbol, el consumo y los jóvenes, el narcotráfico y la justicia, por citar solo algunos. 
jurado como las propias demarcaciones de los autores de las obras era un uso generalizado del término "etnográfico" o "etnografía", el trazado de una frontera reconocida, más allá de que no necesariamente supusiera significados homólogos.

Casi con seguridad, no haya mucho que hoy llame la atención en todo esto. En una altísima proporción, quienes participan del amplio espacio rotulado como "antropología social" (o, en menor medida, "cultural") en la Argentina están convencidos que su tarea es hacer "etnografía". Podría aseverar, sin riesgo a equivocarme demasiado, que "lo etnográfico" caracteriza un modo distintivo de actividad intelectual, que se extiende incluso más allá de los límites de lo considerado como "antropología social", siendo practicado por especialistas en educación, comunicación, trabajo social, sociología y psicología social, entre otras. Claro está que la gran difusión y aprobación que alcanzó la producción definida como "etnográfica" en la Argentina en los últimos veinte años no es un caso aislado, sino que forma parte de un proceso global, donde "antropología" y "etnografía" se han vuelto equivalentes, lo que ha promovido un fuerte debate (Ingold, 2008, 2014, 2017; Da Col y Graeber, 2011; Da Col, 2017; Howell, 2017; Miller, 2017). Estas discusiones, aunque no generalizadas, también llegaron a la Argentina (Visacovsky, 2017; Guber, 2018; Balbi, 2015 y 2020), si bien en un contexto disciplinar muy diferente al de las antropologías de las academias norteamericanas y europeas. Esta situación de consenso disciplinar podría ser leída en términos de lo que Thomas Kuhn ha denominado ciencia normal. Kuhn sostuvo que, en los períodos de ciencia normal, la matriz disciplinaria conformada por teorías, instrumentos, valores y supuestos metafísicos permanecen estables, haciendo posible que los científicos desarrollen sus tareas como si se tratase de la resolución de rompecabezas o acertijos. Precisamente, Kuhn definió esta matriz como un paradigma, ejemplo o modelo de resolución de rompecabezas o acertijos, en la medida que quien intenta resolverlos no transita un territorio desconocido sino, por el contrario, familiar: por ejemplo, conoce los métodos o procedimientos para arribar a una solución que otros han empleado antes (Kuhn, 1985). ${ }^{3}$

3 Soy conciente de las dificultades que puede implicar el uso de las nociones de ciencia normal y paradigma, sobre todo porque presupone acuerdos mucho más amplios y profundos que con seguridad no existen. Desde ya, como reiteraré a lo largo de este trabajo, el significado de lo etnográfico está lejos de ser uno solo, en la Argentina y en el resto del mundo. Ahora bien, diría que, en principio (tal como me lo ha señalado Gabriel Noel, de quien tomo sus palabras en forma casi textual), hay en la Argentina una comunidad reconocible que se asume como "antropológica", que apela a una estrategia que denomina "etnografía", la cual está en el centro de sus modos de producción de conocimiento. De ahí en más, podemos concentrarnos en las diferencias que seguramente encontraremos entre quienes se asumen haciendo "etnografía" (y que son muchas) o entre las similitudes, como la prioridad dada a la investigación empírica, la presencia del investigador en el terreno compartiendo (en mayor o menor medida) la vida cotidiana de las personas que integran la población de su interés y el lugar crucial de las formas de pensar la
Este mismo consenso fue el que advertimos en las obras presentadas al concurso de ensayos. Ahora bien, quien no conoció la situación del campo antropológico argentino anterior al corriente siglo no verá nada extraño ni asombroso en la situación presente. Sin embargo, hubo un tiempo en que hacer trabajo de campo intensivo, prolongado y escribir monografías desde un enfoque que procurase capturar el punto de vista nativo no constituía un programa de investigación académicamente compartido en la Argentina. Este aspecto del desarrollo de los estudios antropológicos en nuestro país no ha recibido todavía suficiente atención. Algunos trabajos se han concentrado en las variadas formas de investigación que adoptó la antropología en la Argentina desde sus inicios hasta los años 1970 (Guber y Visacovsky, 1999 y 2000; Visacovsky y Guber, 2002); sin embargo, no hay todavía trabajos que hayan indagado en la constitución de las formas hoy prevalecientes de abordar la realidad social por parte de la antropología en la Argentina. Hay una razón importante y es que esos cambios se produjeron mucho más recientemente, desde los inicios de los años 1980 en adelante. Todavía la antropología argentina está esperando investigaciones acerca del curso que ha tomado la disciplina luego del retorno democrático en 1983, un período que es tratado muchas veces como si fuera un tiempo homogéneo -como muy bien señalaba Hugo Ratier (2010: 42)- en el que, sencillamente, se habría producido un progreso constante solo alterado por los vaivenes de la política y la economía. ${ }^{4}$

Mi interés principal aquí es abordar, precisamente, el período comprendido entre el retorno democrático a inicios de la década de 1980 y los inicios del corriente siglo, con el propósito de preguntarme cómo lo etnográfico llegó a constituirse en una matriz disciplinaria en la Argentina. Como mostraré, no fue sino en los albores del nuevo siglo que lo etnográfico devino en el modo aceptado y normal de producción de conocimiento antropológico en la Argentina. ¿Cómo se produjo esto? De acuerdo a Kuhn, para que un paradigma se estableciese ("ciencia normal") resultaba indispensable el compromiso con la matriz disciplinaria; y que ese compromiso se obtenía fundamentalmente a través de su inculcación (es decir, la formación científica). Por eso, dirijo mi atención a la enseñanza de la antropología y en particular de la etnografía, ya sea a través de la modalidad universitaria clásica (las cátedras y cursos), grupos de estudio, la difusión a través de libros y artículos específicos o por medio de la práctica misma. Como veremos, la implantación y difusión de lo etnográfico debería verse como un proceso que se inició en los años 1960, pero que recién desde comienzos del corriente siglo logró amplia difusión y fue adoptado como la forma de trabajo bien establecida en la antropología en el país. Para ello, fue decisiva la influencia externa de las

\section{realidad de dicha población.}

4 Excepciones a esta visión del así llamado "presente disciplinar" pueden entreverse en Guber (2002) y Perelman (2015 y 2016). 
antropologías de Estados Unidos, Gran Bretaña y Francia (usualmente llamadas "centrales") para la conformación de un grupo de antropólogos del ámbito local entrenados en el enfoque etnográfico y que, a su vez, pudiesen formar en el mismo a las nuevas generaciones; grupo que, poco después, se ampliará sensiblemente con los antropólogos entrenados en Brasil. Ahora bien, estas condiciones fueron necesarias, pero no suficientes para la recepción, difusión y consolidación del enfoque etnográfico. Roberto Cardoso de Oliveira y Guillermo Ruben han planteado la relevancia del estudio de la institucionalización disciplinar (por caso, en las universidades), que en las academias llamadas "periféricas" presenta peculiaridades tales como las tensiones resultantes de la diversidad de paradigmas (o si se prefiere, perspectivas) coexistentes (Cardoso de Oliveira, 1988; Cardoso de Oliveira y Ruben, 1995). Quienes impulsaban una antropología cuyo núcleo motor fuese lo etnográfico no pudieron establecerlo como nueva matriz disciplinar hasta que lograron instituir formas de enseñanza y práctica científica autonomizadas, diferenciadas de aquellas llevadas a cabo en los principales centros académicos del país, en los cuales el enfoque etnográfico debía lidiar con otras perspectivas sobre cómo practicar la disciplina. La posibilidad de orientar carreras completas desde el enfoque etnográfico llegaría de la mano de los posgrados (específicamente, maestrías) inaugurados desde mediados de la década de 1990, cuyos profesores provendrán inicialmente del grupo mencionado anteriormente. Con el entrenamiento de nuevas generaciones, el enfoque se amplió ostensiblemente, influyendo en todos los centros académicos y dando lugar a un corpus cada vez más importante de escritura etnográfica sobre la Argentina.

El artículo consta de seis secciones que siguen un ordenamiento diacrónico de la institución de lo etnográfico. Buenos Aires es el escenario principal, puesto que figuras claves del desarrollo de lo etnográfico tuvieron a dicha ciudad y sus instituciones académicas como ámbito principal de sus acciones, lo cual no implica desatender la importancia de lugares como La Plata, Rosario o Misiones, como se verá. También, porque es en Buenos Aires donde es posible rastrear de modo muy claro las tensiones de lo etnográfico con otras formas de definición disciplinar. Las dos primeras secciones ponen énfasis en el desarrollo local naciente de una matriz disciplinar etnográfica, destacando particularmente el papel de Esther Hermitte y Rosana Guber, ambas con formación antropológica de posgrado en los Estados Unidos. Respecto a la labor de Hermitte, destaco especialmente su rol como formadora y su capacidad para crear grupos y establecer vínculos entre instituciones e investigadores entre los años 1960 hasta su muerte en 1990. Guber, discípula de Hermitte, prosiguió esta tarea, convirtiéndose en una figura clave de la antropología argentina, en la medida que formuló un programa disciplinario cuyo núcleo fue el enfoque etnográfico para el cual, además, elaboró una genealogía local, de modo tal que las nuevas generaciones pudiesen percibirse en tanto descendientes al compartir orígenes comunes. Su programa disciplinar puede descubrirse en El Salvaje Metropolitano (1991), que abordo en la tercera sección. En la cuarta, muestro algunos ejemplos de antropólogos argentinos contemporáneos a Guber que llevaban a cabo trabajo de campo desde perspectivas próximas, destacando especialmente la tarea de Mauricio Boivin liderando un grupo de investigación desde la segunda mitad de los años 1980 y buena parte de los 1990. En la quinta sección expongo el papel decisivo de la antropología brasileña en el curso de los años 1990, tanto en la legitimación de un modo de enseñar y practicar la disciplina como en la ampliación del grupo de antropólogos formados en el enfoque etnográfico. Como consecuencia de esto, muestro en la sexta y última sección cómo fue posible reorientar la práctica de la antropología a través de los posgrados a partir de inicios del corriente siglo, lo que permitió una amplia redefinición disciplinar.

\section{El trabajo de campo y la etnografía en la década de 1980, con especial referencia a Buenos Aires}

Desde los inicios de la antropología en la Argentina fueron practicadas distintas formas de trabajo de campo por etnólogos y especialistas en folklore. No es mi intención aquí dedicarme a las características que asumió ese tipo de producción entre fines del siglo XIX y la segunda mitad del siglo $X X$, sino situarme en una etapa muy próxima a los inicios de los años 1980. En el curso de la década de 1960 y hasta mediados de la de 1970, un conjunto heterogéneo de investigadores gestó estudios basados en las formas de trabajo establecidas en las academias de antropología social y cultural de Estados Unidos, Francia e Inglaterra, con la sola excepción de Santiago Bilbao (1930-2006), quien siguió un desarrollo propio (Guber, 2010a; Visacovsky, 2002). Ellos fueron María Esther Álvarez de Hermitte (19211990), doctorada en la Universidad de Chicago; Leopoldo Bartolomé (1942-2013), doctorado en la Universidad de Wisconsin; Eduardo Archetti (1943-2005), doctorado en la École Pratique des Hautes Études y Hebe M. C. Vessuri (1942), doctorada en la Universidad de Oxford. Estos investigadores llevaron adelante sus indagaciones mediante trabajos de campo intensivos en diferentes zonas del país, a la vez que expusieron sus resultados en la forma de monografías y artículos en los que las descripciones analíticas constituyeron la parte esencial. A la vez, apelaron a enfoques diversos que podían ir desde la corriente norteamericana de economía política en estudios del campesinado (Sidney Mintz, Charles Wagley, Eric Wolf) al neomarxismo francés de Maurice Godelier (Guber y Visacovsky, 2000).

El escenario de violencia y militarización de la política 
llevaron a que Bilbao y Vessuri escapasen en 1975 de la represión militar en Tucumán (Guber 2010b, 21-22; Visacovsky 2006, 174); ${ }^{5}$ lo que también llevó a Archetti junto a su compañera Kristi Anne Stølen a concluir el trabajo de campo y partir rumbo a Noruega. Algo diferente sucedió con Bartolomé, quien se asentó en Posadas, donde abriría en 1975 una nueva carrera de antropología en la Universidad Nacional de Misiones (creada dos años antes): la Licenciatura en Antropología Social, la cual funcionó sin interrupción durante la dictadura militar, autodenominada "Proceso de Reorganización Nacional" (1976-1983) y continúa en el presente. Por su parte, Hermitte permaneció en la Argentina trabajando en el Instituto de Desarrollo Económico y Social (en adelante, IDES), uno de los espacios en los que fue posible desarrollar actividades académicas alternativas a las existentes en las universidades. Allí, en 1974 creó el Centro de Antropología Social (en adelante, CAS), donde pudo continuar dictando cursos sobre trabajo de campo y antropología médica. Hermitte tendrá un papel central en la difusión en la Argentina de las corrientes vinculadas con la antropología social y cultural, así como del desarrollo del trabajo de campo intensivo, desempeñando un rol decisivo en la reorganización de la carrera de CA-UBA desde 1984, particularmente de la orientación sociocultural (Guber, 2018). Había realizado su doctorado en 1964 bajo la dirección de Julian Pitt-Rivers, con una tesis sobre los mayas tzeltales (habitantes de las tierras altas centrales de Chiapas), regresando al país en 1965 (Guber, 2018). Hermitte se sumó al plantel de profesores del Departamento de CA-UBA, pero renunció después de la "Noche de los Bastones Largos" del 29 de julio de 1966, la violenta ocupación y represión por parte de la Policía Federal Argentina a los estudiantes y profesores de cinco facultades de la UBA que se oponían a la intervención de las universidades por parte de la dictadura militar presidida por Juan Carlos Onganía. Proseguiría su labor en el Instituto Torcuato Di Tella; con el apoyo del Consejo Federal de Inversiones (CFI), Ilevaría adelante dos proyectos desde una perspectiva aplicada. Entre 1969-1971 realizó un estudio sobre la situación social de los grupos Qom y Wichi en Chaco, con la asistencia de Alejandro Isla (1944-2019, graduado en Antropología por la UNLP y Doctorado en la UBA en 1996) y del historiador Nicolás Iñigo Carreras (Hermitte, Isla e Iñigo Carrera 1996). Entre 1982-1984 Hermitte encabezó un equipo conformado por tres jóvenes egresados de la carrera de CA-UBA, Mauricio Boivin, Sofía Ticornia y Rosana Guber, más la egresada de la carrera de Sociología, Victoria Casabona. Desde el Programa Buenos Aires de la Facultad Latinoamericana de Ciencias Sociales (FLACSO) y financiada por la Fundación Interamericana, el equipo llevó adelante un proyecto de investigación sobre villas de emergencia en el Gran Buenos Aires (Hermitte, Boivin, Casabona, Guber y Tiscornia, 1983; Casabona y Guber,

5 El 5 de febrero de 1975, la presidenta María Estela Martínez de Perón firmó el decreto que dio inicio al Operativo Independencia, concebido para combatir la guerrilla en la Provincia de Tucumán.
1985; Hermitte y Boivin, 1985). Estos dos últimos textos formaron parte de un conjunto de ponencias presentadas en el simposio sobre "Relocalización Compulsiva y Antropología Urbana", llevado a cabo en Vancouver (Canadá) en agosto de 1983, en el marco del XI Congreso Internacional de Ciencias Antropológicas y Etnológicas. Ya con el retorno democrático, Hermitte ingresó al Consejo Nacional de Investigaciones Científicas y Técnicas (CONICET) y al plantel de profesores de la CA-UBA (Guber, 2018 a y b).

La carrera a la que se sumaba Hermitte (de la que fui estudiante entre 1979 y 1984) había estado hegemonizada durante los años de la última dictadura por los enfoques fenomenológicos de Marcelo Bórmida (1925-1978) y sus discípulos, en lo que respecta a los estudios etnológicos (es decir, poblaciones indígenas principalmente de la región chaqueña y patagónica). Hasta 1984, los programas de las materias excluían a Boas, Margaret Mead, Durkheim, Mauss, Malinowski, Radcliffe-Brown, Evans-Pritchard, Gluckman, LéviStrauss, Godelier, Victor Turner, Mary Douglas o Sahlins. ${ }^{6}$ Si se considerase solo la perspectiva de Bórmida, quienes fueron estudiantes por entonces habrían transitado la carrera ignorando la crisis del estructural funcionalismo en Inglaterra y la emergencia de la Escuela de Manchester, el neoevolucionismo, el materialismo cultural, la Etnociencia, el estructuralismo francés o el giro interpretativo. No obstante, había excepciones importantes. Edgardo Cordeu (1935-2017) difundía muchos autores clásicos de la antropología norteamericana, francesa y británica en la materia Etnología General, especialmente sobre problemáticas vinculadas a las representaciones, las creencias y el simbolismo. Por su parte, Alejandra Siffredi (1935) incluía en su curso de Etnología Americana una importante cantidad y variedad de textos etnográficos sobre poblaciones cazadoras-recolectoras de todo el continente americano, transmitiendo el valor de los estudios regionales comparativos; esto no era un asunto menor, pues la lectura de monografías etnográficas clásicas no constituía una vía de aprendizaje antropológico reconocido por entonces. A la vez, el curso ofrecía la posibilidad de acceder a la ecología cultural y el neoevolucionismo de Julian Steward o el materialismo cultural de Leslie White, ausentes en el

\footnotetext{
6 Los autores estelares de aquellos años eran, entre otros, el teólogo protestante alemán Rudolf Otto (1869-1937) con su idea de lo sagrado como lo numinoso; el historiador holandés Gerardus van der Leeuw (1890-1950) y su fenomenología de la religión; el historiador de las religiones rumano Mircea Eliade (1907-1986) y la manifestación de lo sagrado (hierofanía); el etnólogo alemán Adolf Ellegard Jensen (1899-1965); el filósofo e historiador de las ideas francés Georges Gusdorf (1912-2000); el neurólogo y psiquiatra austríaco, fundador de la logoterapia, Viktor Emil Frankl (1905-1997); el etnólogo italiano Ernesto de Martino (1908-1965); y además, el mismo Bórmida. Pese a que faltan más estudios, los autores y perspectivas enseñados antes de 1984 en Buenos Aires estaban en consonancia con la fuerte oposición de Bórmida hacia la antropología social, un sinónimo para él de funcionalismo, sociología anglosajona y, en definitiva, liberalismo (Visacovsky, Guber y Gurevich, 1977; Guber, 2006)
} 
resto de la carrera.

A partir del retorno democrático en 1983, una de las posiciones preponderantes entre muchos antropólogos argentinos fue la de reducir las teorías e investigaciones de la antropología cultural y social norteamericana y británica a una mezcla de empirismo ingenuo e ideología colonialista. Es cierto que perduraba en el campo disciplinar una fuerte desconexión respecto a la producción científica en otros ámbitos académicos internacionales, acentuada por la imposibilidad de contar con colecciones actualizadas en las bibliotecas, en razón del insuficiente financiamiento en educación, ciencia y tecnología. También reaparecían puntos de vista forjados en los años 1960 y el primer lustro de los 1970, tales como "El modelo antropológico clásico" de Eduardo Menéndez (nacido en 1934 y egresado de CA-UBA en 1963). Este fue difundido a través de cátedras como la de "Antropología" del Ciclo Básico Común de la UBA (desde 1985), cuya Profesora Titular era Mirtha Lischetti (nacida en 1939, egresada de CAUBA en 1965); según su autor, este modelo consistía en "la perspectiva antropológica producida básicamente por el funcionalismo británico y por el culturalismo norteamericano entre 1920 y 1950, y que no sólo devino hegemónica, sino que operó hasta la actualidad como parte nuclear del imaginario antropológico" (Menéndez 2002, 81). ${ }^{7}$ Esta generalización, que atribuía una presunta homogeneidad a escuelas, teorías y estilos de investigación etnográfica profundamente disímiles, iba acompañada de una resistencia bastante importante a la práctica del trabajo de campo etnográfico ${ }^{8}$ acorde con la errónea identificación de la investigación empírica con empirismo.

Con este panorama, Hermitte se sumó en 1984 a la materia "Metodología y Técnica de la Investigación Etnológica", que contó además con el antropólogo Carlos Herrán (1939-2013), Malvina Segre (19262013) -profesora de estadística que había sido estrecha colaboradora de Gino Germani y de la misma Hermitte- y con el filósofo Félix Schuster (19352017). Cada uno se ocupó de una temática específica: Schuster, problemas epistemológicos; Segre, el uso de estadísticas en ciencias sociales; Hermitte y Herrán, la metodología del trabajo de campo en antropología

\footnotetext{
7 La primera versión de "El modelo antropológico clásico" circuló en forma mecanografiada en 1975. Un análisis contextual y crítico puede verse en Guber (2008, 85-90). No deja de llamar la atención el rechazo de la antropología social británica como "funcionalista" por Bórmida y Menéndez; aunque desde posiciones políticas opuestas, los unía el antiliberalismo que, presuntamente, subyacía a la antropología social (o a aquello con lo cual la identificaban).

8 Como muestra, hacia fines de los años 1980 un grupo de estudiantes llevó a cabo una performance: representaron un cortejo fúnebre por los pasillos de la FFyL-UBA, transportando un ataúd que se suponía contenía los restos de la antropología funcionalista. Según (Lebedinsky, 1994), el ataúd contenía los restos del "funcionalismo", que fue finalmente quemado, simbolizando la caducidad de dicho paradigma.
}

social. ${ }^{9}$ Guber, que había integrado el equipo de Hermitte que investigó sobre villas miseria, estaría a cargo de los trabajos prácticos.

Al reestructurarse el plan de estudios en la UBA en 1985, Hermitte obtuvo por concurso el cargo de Profesora Titular de la nueva materia, Metodología y Técnicas de la Investigación de Campo (en adelante, MYTIC). Por su parte, Guber ganó el de Profesora Adjunta; a partir de entonces, iniciaría un camino dirigido a transmitir la concepción del trabajo de campo etnográfico basado en la co-residencia y la estadía prolongada, tal como el mismo venía desarrollándose desde hacía décadas en los centros académicos más importantes del mundo. Y, aún más: pudo imaginar un programa para la antropología argentina.

\section{Los años 1990: controversias porteñas sobre la etnografía y el trabajo de campo}

Nacida en 1957, Guber se había graduado como Licenciada en CA-UBA en 1982 con una tesis sobre la identidad de los inmigrantes judíos ashkenazim llegados a Buenos Aires desde Europa Central, bajo la dirección de Manuel María Rocca, profesor de Folklore. ${ }^{10}$ Como sucedía con muchos estudiantes entonces, Guber participó de espacios alternativos de formación. Como me lo planteara personalmente, ella pretendía (como muchos de su generación) hacer una antropología diferente a la que enseñaban y practicaban Bórmida y sus discípulos; fundamentalmente, ellos querían hacer una antropología de las sociedades complejas. Guber llevó a cabo varios de los cursos que brindaba el IDES, particularmente los que dictaba el CAS. Allí se encontraría con Hermitte, hecho que tendría una relevancia central en su carrera.

Como ya señalé, en 1982 (ya como parte del equipo de investigación dirigido por Hermitte) Guber realizó trabajo de campo con pobladores de villas miseria en el Gran Buenos Aires, con el fin de estudiar los prejuicios, la discriminación y la segregación urbana. Con este material realizó la tesis que le permitiría graduarse en la Maestría en Ciencias Sociales en FLACSO. Tras el ya mencionado paso como auxiliar docente en 1984 y la

\footnotetext{
9 Herrán había colaborado con Hermitte cuando ella había radicado su trabajo en el Instituto Torcuato Di Tella, luego de su ya mencionada renuncia a la UBA en 1966; con el apoyo del CFI llevaron adelante un proyecto sobre las cooperativas de tejedores de ponchos y de pequeños productores de pimentón en la provincia de Catamarca (Hermitte y Herrán, 1970). En calidad de asistente, Herrán también había acompañado a Hermitte en 1974, participando del grupo que ella había formado en el Consejo Latinoamericano de Ciencias Sociales (CLACSO) con el fin de debatir la noción de "articulación social", que habían integrado importantes antropólogos de Estados Unidos y América Latina, entre ellos, Archetti, Vessuri y Bartolomé, compilador junto a Hermitte del libro que reunió los trabajos presentados volumen publicó la compilación (Hermitte y Bartolomé 1977). Para un análisis de la trayectoria de Herrán, véase (Guber, 2017).

10 Guber publicaría casi de inmediato partes de su tesis (Guber, 1984), como consecuencia de la obtención de una segunda mención en el concurso Coca Cola en las Artes y en las Ciencias.
} 
obtención por concurso en 1985 del cargo de Profesora Adjunta de MYTIC, ${ }^{11}$ Guber también ingresó a la Carrera de Investigador Científico del CONICET. ${ }^{12}$ Junto con otros colegas, Guber tuvo un rol destacado en la organización del II Congreso de Antropología Social (en adelante, CAAS) celebrado en Buenos Aires en 1986. Y en 1988, Guber se marchó a los Estados Unidos para realizar estudios de posgrado en el Departamento de Antropología en la Universidad Johns Hopkins (Baltimore, Maryland), donde obtendría los títulos de Master of Arts (1992) y el doctorado (1999).

Debido a la enfermedad de Hermitte (quien fallecería en 1990) y a la partida de Guber, MYTIC se reorganizaría en 1990. El Departamento propuso que la materia estuviese un cuatrimestre a cargo de Hugo Ratier (1934-2021) y el siguiente a cargo de Graciela Batallán. Ratier había trabajado en los inicios de los años 1960 en villas miseria en Isla Maciel, en Dock Sud, Avellaneda (provincia de Buenos Aires), publicando en 1971 dos textos orientados a la divulgación, que tuvieron una enorme difusión: Villeros y Villas Miseria y El cabecita negra (Guber, 1999). ${ }^{13}$ Por su parte, Batallán se había graduado en Historia en la Universidad Nacional de Rosario (en adelante, UNR); en los inicios de los años 1980, junto a Elena Achilli (investigadora en el campo de la antropología de la educación) había participado en la Red de Investigaciones Cualitativas de la Realidad Escolar (RINCUARE), que dirigía la historiadora y antropóloga estadounidense, nacionalizada mexicana, Elsie Rockwell. Esta había llevado adelante un programa de investigaciones sobre escuelas, donde los abordajes etnográficos tenían un papel central. Como investigadora en el Museo Etnográfico "Juan B. Ambrosetti", dependiente de la Facultad de Filosofía y Letras de la Universidad de Buenos Aires (en adelante, FFyL-UBA) y junto a María Rosa Neufeld (nacida en Buenos Aires en 1941, egresada de CA-UBA en 1967 y profesora Asociada de Antropología Sistemática I-Organización Social y Política desde 1985), Batallán creó el Programa de Antropología y Educación con sede en el Instituto de Ciencias Antropológicas de la UBA (en adelante, ICAUBA) en 1992.

\footnotetext{
11 Integraban también la cátedra Victoria Casabona, Mónica Lacarrieu, Ariel Gravano y Claudia Girola, entre otros.

12 Entre 1984 y 1985, Guber, Raúl Díaz, Martín Sorter (fallecido en 2003) y yo conformamos un grupo de estudio extra-universitario, dedicado a la lectura y discusión bibliográfica sobre diferentes enfoques de las ideologías (en especial, la tradición marxista), con el fin de analizar posibles conexiones con la antropología. El grupo se autodenominó "Yatay", en razón de que las reuniones semanales se realizaban mayormente en mi hogar, ubicado precisamente en esa calle de la Ciudad de Buenos Aires.

13 Exiliado en 1976, profesor y luego Jefe del Departamento de Sociología y Antropología en Campina Grande, en el Estado de Paraíba, había cursado el doctorado en el Programa de Posgraduación en Antropología Social del Museo Nacional de Rio de Janeiro (en adelante PPGAS-UFRJ). Ya de vuelta en Argentina, se integró a CAUBA, siendo clave su labor en la génesis del campo de estudios rurales y la creación de la Licenciatura en Antropología en la Universidad Nacional del Centro de la Provincia de Buenos Aires, con sede en la ciudad de Olavarría.
}

En ese mismo año, el Departamento confirmó a Batallán como Profesora Titular interina de MYTIC. Este hecho coincidió con el regreso de Guber a la Argentina, quien debía reasumir sus funciones en la cátedra como Profesora Adjunta Regular. No obstante, Guber terminó aceptando la designación interina de Batallán. Esta propuso una orientación fuertemente epistemológica, privilegiando los debates sobre el lugar de la hermenéutica y las perspectivas interpretativas en ciencias sociales; de ahí que en el programa prevalecieran las lecturas de filósofos como Alfred Schutz, Charles Taylor, Ágnes Heller, Paul Ricoeur y Hans-Georg Gadamer. Asimismo, también se destacaba el enfoque de Anthony Giddens y la doble hermenéutica, así como de Harold Garfinkel y la Etnometodología. En el campo estrictamente antropológico, además de Rockwell, el autor principal era Clifford Geertz y su teoría interpretativa de la cultura. Por sugerencia de Guber, Batallán incluyó al antropólogo checo Ladislav Holy, quien traía un replanteamiento de la observación participante desde el punto de vista hermenéutico. ${ }^{14}$ En concordancia con la posición predominante en la institución así como en otros centros académicos del país, tanto la antropología clásica como los análisis sobre experiencias de trabajo de campo tenían poco lugar y solo aparecerían de vez en cuando como ejemplos de una antropología empirista y colonial. En relación con libros que introdujeran a los estudiantes a la práctica de la investigación etnográfica, Batallán aceptó incluir en la bibliografía solo los capítulos de EI Salvaje Metropolitano de Guber (al que dedicaremos la sección siguiente) centrados en la entrevista, mientras que otros temas (como la observación participante, el registro o la escritura) fueron tratados con libros como Etnografía. Métodos de investigación, de los sociólogos Martyn Hammersley y Paul Atkinson. ${ }^{15}$ Paralelamente, fueron ganando terreno algunos trabajos de la llamada "antropología posmoderna", tales como "Las etnografías como textos" de George Marcus y Dick Cushman de 1982 y "Sobre la autoridad etnográfica", de James Clifford de $1983,{ }^{16}$ que tuvieron amplia difusión en la Argentina a través de una compilación de artículos traducidos y publicados por Carlos Reynoso, profesor de la CA-UBA (Reynoso, 1991). ${ }^{17}$

Si los mayores intereses de Batallán estaban centrados en los problemas epistemológicos de las ciencias sociales, Guber ponía mucho más énfasis en la enseñanza de las peculiaridades del trabajo de campo etnográfico a través de la lectura de monografías. Si bien la materia contaba entre sus textos obligatorios con unas pocas monografías etnográficas del llamado "período clásico",

\footnotetext{
14 Guber había conocido la compilación de Roy Ellen (publicada en 1984), Ethnographic Research. A Guide of General Conduct (uno de cuyos capítulos estaba a cargo de Holy) a través de Hermitte y Boivin. 15 El libro original, Ethnography: Principles in Practice, había sido publicado por Routledge en 1983; la primera edición en español había sido en 1994

16 Su perspectiva sobre la antropología y la teoría y epistemología de las ciencias sociales puede verse en Batallán (1995) y Batallán y García (1992).

17 Ver nota 22.
} 
Guber pudo añadir al programa Los Argonautas del pacífico Occidental de Bronislaw Malinowski (en especial, su célebre introducción). Algunas de las monografías incorporadas a la bibliografía fueron: Aprendiendo a trabajar de Paul Willis (que Akal había publicado en 1988 en español, siendo el original en inglés de 1977); De cadenas y de hombres (tal como se conoció en español, publicada en 1988 por Siglo Veintiuno la obra del sociólogo francés Robert Linhart, cuyo título original de 1978 era L'Établi); La organización social de la muerte, del sociólogo David Sudnow, publicado por Tiempo Contemporáneo en 1971, cuyo original era de 1967); y Los príncipes de Naranja: un ensayo de método antropohistórico (de las lecturas preferidas de Batallán), de Paul Friedrich, publicada en México por Grijalbo en 1991 (el original era de 1986). También sobresalía Behind Many Masks: Ethnography and Impression Management in a Himalayan Village, un texto de Gerald D. Berreman de 1962 que había introducido anteriormente Hermitte y que circuló en una versión inédita traducido por Casabona.

Además, la materia pretendía orientar a los estudiantes en sus primeros pasos en el trabajo de campo. Los trabajos prácticos consistían, precisamente, en una serie de ejercicios bajo la guía de los auxiliares docentes. Sobre la base de algunas consignas, los estudiantes debían elegir una temática (excepto ocasiones especiales en que la cátedra sugirió alguna en común), problematizarla, seleccionar una población y lugares o escenarios de estudio, realizar observaciones y entrevistas en profundidad, confeccionar registros comentados y redactar un informe final. Identificar temas de interés y transformarlos en algo susceptible de ser abordado por la antropología no era tarea sencilla, tanto por las dificultades mismas de la tarea como por las condiciones de trabajo de los auxiliares, que debían atender comisiones de trabajos prácticos muy numerosas. Por otra parte, las prácticas generaban tensiones entre los estudiantes. Algunos las cuestionaban más o menos en los mismos términos que lo hacían algunos profesores, es decir, como "empirismo burdo" y "resabio colonialista", expresiones que también empleaban para calificar las monografías etnográficas del programa, en especial las clásicas. No pocas veces se suscitaron acaloradas discusiones en las clases entre algunos estudiantes y docentes, donde los primeros impugnaban el valor de las prácticas debido, sobre todo, a la imposibilidad de ir al campo sin teorías. Para algunos estudiantes y docentes, el enfoque de la materia era "interpretativista" y "posmoderna", términos a los que adjudicaban un sentido peyorativo. MYTIC se convirtió en un asunto de importancia crucial, tanto para la militancia estudiantil ligada a CA-UBA como para el Departamento. El dictado de la materia transcurrió durante esos años en un clima de zozobra permanente, con frecuentes reuniones del claustro de profesores ante las quejas estudiantiles, las cuales escalaron hasta el nivel de solicitar la apertura de una cátedra paralela con un enfoque diferente. ${ }^{18}$

En este difícil escenario, Guber propuso llevar adelante una actividad que contribuyese a debatir la metodología de la investigación en antropología y ciencias sociales. El lugar elegido fue el IDES donde, recordemos, Hermitte había creado el CAS; allí Guber había organizado el "Grupo-Taller de Trabajo de Campo Etnográfico" (en adelante, GTTCE), integrado por estudiantes de diferentes carreras de antropología y otras ciencias sociales, ${ }^{19}$ cuyo propósito era la lectura y discusión de textos (tanto propios como de invitados), entre los cuales estaban los proyectos de investigación de los participantes para sus tesis de graduación. Este grupo trabajó, precisamente, junto con la cátedra en la organización de las "Primeras Jornadas de Etnografía y Métodos Cualitativos" (en adelante, JEMC), que se llevaron a cabo entre el 9 y el 10 de junio de 1994, un evento que tendría continuidad ininterrumpida desde entonces. En aquel entonces, una multitud se congregó para discutir acerca de la etnografía en relación con debates epistemológicos y metodológicos más recientes en antropología y ciencias sociales. De ahí en más, las JEMC se plantearon como un espacio novedoso de debate en el medio local sobre la especificidad, aportes y limitaciones de los métodos cualitativos y el trabajo de campo etnográfico.

En esos años comenzaron a aparecer algunas publicaciones sobre el trabajo de campo y la escritura llamada etnográfica. Así, en 1994 Guber y yo publicamos sendos artículos en la revista Relaciones de la Sociedad Argentina de Antropología (Guber, 1993-1994; Visacovsky, 19931994). Y cinco de las ponencias presentadas en las JEMC fueron publicadas rápidamente en la novel Publicar en Antropología y Ciencias Sociales, la revista del Colegio de Graduados en Antropología (Visacovsky, 1995; Guber, 1995; Abduca, 1995; Gravano, 1995; Guebel y Zuleta, 1995). Estos fueron los primeros artículos sobre trabajo de campo producidos por antropólogos argentinos sobre sus propias experiencias, desde los realizados por Hermitte y Vessuri en la década de 1970. Paralelamente, entre 1994 y 1997 Guber encabezó un proyecto financiado por la UBA, titulado "Antropología y Nación. La invención etnográfica de la Argentina". ${ }^{20}$ En el mismo se abordaron varias cuestiones, tales como los orígenes y el perfil de la carrera de CA-UBA (Visacovsky, Guber y Gurevich, 1997;

18 A través de rumores, circularon nombres de diversos profesores del Departamento que asumirían el compromiso de dictar una materia diferente, aunque la propuesta más concreta (ya que consistió en la presentación de un programa) fue la del epistemólogo Juan Samaja (1941-2007), quien a la sazón estaba al frente de una cátedra de metodología de la investigación psicológica en la Facultad de Psicología de la UBA.

19 Participaron de ese grupo, entre otros, Sabina Frederic, Alejandro Grimson, Rolando Silla, Virginia Vecchioli, Brígida Renoldi, Andrea Mastrángelo, Carolina Feito, Patricia Fasano, Eugenia Ruiz Bry, Patricia Durand, Iris Fihman, Christine Danklemaer, Elias Prudant, José L. Ciotta y Norma Micci.

20 Participaron del mismo Laura Vugman, Ana Beatriz Domínguez Mon, Estela Gurevich (fallecida en 2018) y yo; más tarde se agregarían Lorenzo Cañás Bottos y Pablo Perazzi. 
Guber y Visacovsky, 2006), la memoria colectiva de los antropólogos de la UBA (Guber y Visacovsky, 1997-1998) y el desarrollo de una incipiente corriente etnográfica entre mediados de los años 1960 y la primera mitad de los 1970 (Guber y Visacovsky, 1999 y 2000). Como parte de los desarrollos del proyecto, a fines de 2002 Guber y yo coordinamos un volumen colectivo sobre los estilos de trabajo de campo en la Argentina, en el amplio campo de las "ciencias antropológicas" (Visacovsky y Guber, 2002), que incluiría el artículo inédito de Hermitte, "La observación por medio de la participación" y la republicación de "La Observación Participante en Tucumán 1972", de Vessuri. El proyecto estaba impulsado por una preocupación que procedía de la experiencia tan conflictiva de la enseñanza del trabajo de campo y una suerte de conjetura: acaso, un examen de la historia de constitución del campo mismo de la antropología social en el país proporcionaría la respuesta al presente.

Como se advierte, al menos en el ámbito de la antropología social en Buenos Aires, la década de 1990 fue un tiempo de fuertes contrastes, donde se combinaban profundos desacuerdos acerca del enfoque de la investigación y de cómo llevarla a cabo; divergencias que no estaban disociadas de las concepciones generales del quehacer antropológico y de la antropología social como categoría social, como identidad (Guber, 2001a). No obstante, la etnografía (o lo que se entendía por ella entonces) emergía como una alternativa plausible para constituirse en un programa disciplinario.

\section{EI Salvaje Metropolitano: un programa para la antropología social en la Argentina}

Con el escenario expuesto en el acápite precedente, circulaba ya una obra fundamental para la antropología argentina de los últimos treinta años: El Salvaje Metropolitano. A través de un libro que, en principio, aparecía como un manual metodológico, Guber postulaba un auténtico programa disciplinar, consistente en sentar las bases de la investigación empírica de la realidad argentina a través de los medios que proporcionaba la antropología social, a los fines de generar un corpus de estudios que, por el momento, era escaso.

Publicado en 1991 en la colección Comunicación y Sociedad de la Editorial Legasa, que dirigía el escritor, periodista y teórico de la comunicación Aníbal Ford (1934-2009), Guber había iniciado su escritura en 1987, concluyéndola en 1988, antes de irse a Estados Unidos. Según el testimonio que me brindara la propia Guber, el libro fue publicado años después merced a la gestión de Ford y del escritor y crítico literario Jorge Lafforgue (1935). En esa primera edición, al título principal le seguía el subtítulo A la vuelta de la antropología postmoderna. Reconstrucción del conocimiento social en el trabajo de campo (la primera oración desaparecería en la reedición de 2004). Aunque el libro no pretendía centrarse en ni reducirse a los problemas de los estudios antropológicos en contextos urbanos, el título aludía claramente a dicha tendencia entre los investigadores locales a estudiarlos. La alusión a un "salvaje metropolitano" evocaba la cuestión de cómo transformar lo familiar en exótico, planteada por Roberto Da Matta (1978), tema bastante frecuente en las discusiones metodológicas por entonces. Respecto a la mención de la llamada "antropología posmoderna", la propia Guber en una comunicación personal me señaló que fue una sugerencia de Aníbal Ford. ${ }^{21}$

Por ese entonces, la bibliografía en español sobre metodología etnográfica era casi inexistente; mucho menos escrita por una antropóloga argentina. Por ejemplo, en 1957 la editorial Nova había publicado una traducción de Méthode de l'ethnographie, del antropólogo francés Marcel Griaule (1957), el mismo año de la edición de Presses universitaires de France. Como ya señalé, en 1974 Hermitte había escrito "La observación por medio de la participación", que se difundió en su versión inédita mecanografiada a través de la oficina de publicaciones del Centro de Estudiantes de la FFyL-UBA. Por su parte, Vessuri aportó dos trabajos; el ya mencionado "La observación participante en Tucumán 1972", donde analizó los límites del trabajo de campo en la convulsionada Tucumán de inicios de los años 1970 (Vessuri, 1973a); y el mismo año, "Técnicas de recolección de datos en la Antropología Social" (Vessuri, 1973b). Por cierto, también circulaban libros y artículos metodológicos en ciencias sociales, pero ninguno de ellos era propiamente etnográfico. En consecuencia, El

21 Aunque los debates sobre la posmodernidad (sobre todo en filosofía y crítica literaria) se iniciaron en los años 1980 (la revista Punto de Vista fue uno de sus principales difusores), las discusiones en la antropología llegaron a partir de inicios de la década siguiente. Uno de sus impulsores fue Carlos Reynoso, profesor de "Teorías Antropológicas Contemporáneas" en la CA-UBA quien, a través de sus clases y escritos, llevó adelante una crítica sin cuartel contra el trabajo de campo etnográfico, las teorías interpretativas y el posmodernismo en antropología. No obstante, Reynoso había desarrollado una meritoria contribución a la difusión de tales corrientes. A través de la editorial española Gedisa, primero, en 1987, realizó la revisión técnica y escribió el prólogo de La interpretación de las culturas, de Clifford Geertz (publicado originalmente por Basic Books en 1973); segundo, realizó la revisión técnica en 1988 de Islas de Historia, de Marshall Sahlins (cuyo original de The University of Chicago Press es de 1985); y tercero, en 1991, tradujo, compiló y escribió la presentación de El surgimiento de la Antropología Posmoderna, reuniendo a autores como Geertz, Richard A. Shweder, Michael Agar, James Clifford, George E. Marcus, Dick E. Cushman, Marilyn Strathern, Dennis Tedlock y Stephen Tyler. También, Reynoso publicó en el primer número de la revista Publicar del Colegio de Graduados en Antropología un duro ataque al presente disciplinario (Reynoso, 1992a), artículo que fue acompañado por sendos comentarios críticos (Guber, 1992; Visacovsky, 1992), más una respuesta posterior de Reynoso (1992b). Él postulaba que la antropología como disciplina estaba muerta (o pronta a fenecer), debido a la predominancia desde los años 1970 de las corrientes hermenéuticas e interpretativas y a partir de los años 1980 del llamado posmodernismo etnográfico, responsables de haberla expulsado del espacio de la ciencia. Para revertir este proceso, sugería que la antropología debía incorporar teorías y métodos de análisis de redes, teorías de los sistemas complejos adaptativos, el modelo basado en agentes, sintaxis espacial, etc. Varios años después retomó la polémica en Reynoso (2011). 
Salvaje Metropolitano ocupó un lugar hasta entonces vacío.

Para escribirlo, Guber se basó en su formación junto a Hermitte, en su experiencia como profesora en MYTIC y en su aprendizaje como trabajadora de campo. El texto principal está precedido por una presentación a cargo de Casabona (Guber destacaba muy especialmente su labor como coordinadora editorial, además de crítica y comentarista) y prologado por Hermitte. En los agradecimientos, mencionaba la amplia gama de ayuda y colaboración de sus colegas para la concreción del libro, ${ }^{22}$ a quienes caracterizaba como una "tribu de intérpretes, traductores e interlocutores, todos ellos trabajadores de campo", a quienes les reconocía "su tenacidad antropológica" y "su obstinación en reconstruir una disciplina que se quiso ignorar y condenar al olvido"; en definitiva, tal "forma de trabajo" podría "ayudar a recuperar la voz y los modos de quienes, en los años sesenta" habían iniciado "el camino de una antropología argentina", con lo cual habrían "cumplido con una parte importante de nuestra propuesta" (Guber, 1991: 9-10). Esta visión de una disciplina que se quiso desconocer y condenar al olvido reaparecería en los primeros párrafos de la introducción, donde Guber refería a la situación de su generación durante la última dictadura militar ("En 1979, los estudiantes argentinos teníamos muy pocos espacios donde formarnos como antropólogos sociales"), destacando el papel cumplido por la Carrera de Antropología Social de la Universidad Nacional de Misiones (en adelante, CA-UNaM) desde 1975, única en su tipo, así como del IDES.

La primera parte del libro era claramente epistemológica. Guber analizaba la formación histórica de una tradición del trabajo de campo en antropología social, discutiendo el positivismo, el interpretativismo y el papel de la subjetividad en el conocimiento social. También analizaba la especificidad del enfoque antropológico y la construcción de objetos de investigación particulares. En un medio local en donde la especificidad de la antropología estaba puesta en duda (o directamente negada), Guber planteaba como propio de la disciplina el estudio de la diversidad en tanto construcción teórica, la cual se ponía de manifiesto en la singularidad de los casos estudiados. Paralelamente, Guber señalaba la importancia de la perspectiva del actor, ya que "afirmamos que describir y analizar el proceso social en

22 Guber mencionaba a Salomón Jorge (Cacho) Babor, Victoria Barreda, Batallán, Rubens Bayardo, Silvana Campanini, Blanca Carrozzi, Magdalena Chiara, Ana Domínguez Mon, Claudia Giróla, Ariel Gravano, Carmen Guarini, Mónica Lacarrieu, Federico Neiburg, Ana M. Rosato, Sofía Tiscornia y yo. Por otra parte, destacaba especialmente a Mauricio Boivin por haberle facilitado publicaciones recientes, a quienes integraban el programa de Antropología Urbana, dirigido en el ICA-UBA por Carlos Herrán, los integrantes de MYTIC, a Raúl Díaz y Cecilia Luvecce por sus observaciones y a Ana Rosato, con quien en 1985 había abordado la cuestión de la construcción del objeto de conocimiento en el Seminario de Investigación en Antropología Social (UBA), dirigido por Hugo Ratier. su diversidad y singularidad implica rescatar la lógica de la producción material y simbólica de los sujetos sociales" (Guber, 1991:74). También introducía una idea de reflexividad en el trabajo de campo, a la que veía como un proceso que incluía las interacciones, formas de diferenciación y relaciones de reciprocidad entre un investigador con sus teorías, supuestos y sentido común y las perspectivas de los actores (Guber, 1991: 87). Guber se preocupaba por aclarar que, si bien el objeto de investigación es construido, esto no equivalía a caer en el teoricismo, "si es que se tiene claridad acerca de la integración del referente empírico y la perspectiva del actor a la investigación y, más aun, al desarrollo de la teoría misma" (Guber, 1991: 64). No obstante, en la reedición de 2004 por Paidós, ${ }^{23}$ Guber modificaría el párrafo, al plantear que el no caer en el teoricismo constituía "quizás el mayor desafío del conocimiento antropológico y de todo aquel trabajo que se funde en material obtenido por vía etnográfica. La integración entre datos y teoría, y la puesta en diálogo entre ambos, es quizás uno de los puntos de más difícil resolución en la monografía final, que en antropología llamamos «etnografía». El investigador-autor da cuenta de este dilema con su propia creatividad" (Guber, 2004: 33). La noción de etnografía se haría mucho más omnipresente en la segunda edición, dando cuenta de un cambio en el lenguaje disciplinar y, por cierto, en la práctica del mismo.

La segunda parte era (como la propia Guber la definía) más "técnica", ya que desarrollaba cuestiones básicas de la práctica del trabajo de campo: dónde y con quiénes llevar a cabo la investigación, cómo concebir a los informantes, la presentación del investigador en el campo y los roles cambiantes asignados/asumidos en el curso del mismo, la observación con participación (donde problematizaba las concepciones clásicas del "participar para observar"), la importancia de la co-residencia para aprehender la vida cotidiana, las características de la entrevista abierta y no directiva (que definía como "antropológica") y las formas de registro. Guber ilustraba sus argumentos con su propio trabajo de campo, con el de Hermitte, con el procedente de estudios clásicos y con los registros proporcionados por otros antropólogos y antropólogas del medio local.

Desde su primera edición, El Salvaje Metropolitano empezó a formar parte de la bibliografía de la materia de MYTIC, aunque (como ya señalé) solo los capítulos dedicados a la entrevista antropológica eran de lectura obligatoria. Con el paso de los años, El Salvaje Metropolitano se constituyó en un apoyo fundamental para los estudiantes y las nuevas generaciones de

23 La reedición incluiría un nuevo prólogo y varias modificaciones, además de cambios en los títulos de los capítulos. También, Guber eliminó dos apéndices: un análisis del juicio a las juntas militares que formaron parte de los gobiernos de facto entre 1976-1983 apelando a las teorías antropológicas del ritual, por Esther Kaufman; y un texto sobre cine y antropología, por Carmen Guarini. 
investigadores. El libro sería una herramienta principal de difusión y enseñanza del trabajo de campo en la Argentina y en muchos países de habla hispana (el texto se difundió no solo a través de su venta, sino también a través de la reproducción por Internet de versiones digitalizadas no autorizadas), tanto en las carreras de grado como en los posgrados que empezarían a surgir a partir de los primeros años del nuevo siglo (tema del que me ocuparé en la última sección).

En el Prólogo, Esther Hermitte sostenía que en la Argentina "no llegó a consolidarse en los estudios de antropología social la práctica prolongada de campo". Y agregaba: "Por motivos que no detallaremos aquí, la antropología social en la Argentina tiene, por una parte, un comienzo tardío y, por otra, una práctica débil del trabajo de campo que demoraría años en modificarse". Esta afirmación de Hermitte da sentido al libro de Guber, en tanto parte esencial de un proyecto que podía alterar definitivamente esa debilidad atribuida a la práctica del trabajo de campo, sea porque no se lo ejercitaba o porque se lo hacía de manera inapropiada.

\section{Antropólogos y trabajos de campo en los 1980}

De hecho, otros antropólogos y antropólogas estaban practicando formas de trabajo de campo en la Argentina desde los años 1980. Algunos llevaban a cabo estudios sobre poblaciones originarias, tal como Pablo Wright (egresado de CA-UBA en 1981), quien abordó la cosmovisión Toba en el Chaco, comunidad a la que Liliana Tamagno (quien había cursado Antropología en UNLP, debió exiliarse y obtuvo una maestría en la Universidad de Upsala, Suecia) encontró como migrantes asentados en el Gran Buenos Aires; Claudia Briones (egresada de CA-UBA en 1983), sola o con colegas como Miguel Olivera (egresado de CA-UBA en 1983 y fallecido en 1991), investigaba las relaciones entre identidad y etnicidad entre los Mapuche en Neuquén, población que también era abordada por Juan Carlos Radovich (egresado en 1980 de CA-UBA); y Ana María Gorosito Kramer (egresada de la CAUBA en 1974) quien indagaba las relaciones interétnicas y representaciones entre los Mbya guaraní en Misiones. Otros llevaron a cabo investigaciones más en línea con las clásicas regiones del Folklore en la Argentina (el Noroeste, principalmente), aunque con intereses y perspectivas más vinculadas a la antropología social y la sociología, tal como Gabriela Karasik (egresada de la CA-UBA en 1985) con sus investigaciones sobre etnicidad en la puna jujeña. Por otra parte, Ana Rosato (egresada de CA-UBA en 1980 y Magister en FLACSO en 1989) llevaba a cabo trabajo de campo con los pobladores del Delta del Río Paraná dedicados a la caza y la pesca. También destacaban los estudios sobre el mundo del trabajo: Karasik con la industria azucarera; Mabel Grimberg (egresada en 1972 de (A-UBA) con las demandas de salud entre trabajadores de la industria gráfica en Buenos Aires; Federico Neiburg (quien se había formado muy joven en México donde sus padres se habían exiliado) con los obreros de la empresa Loma Negra, productora de cemento, en el partido de Olavarría, en el centro de la Provincia de Buenos Aires. Del mismo modo, hay que mencionar las investigaciones sobre el espacio urbano, como las emprendidas por Ariel Gravano (egresado de CA-UBA en 1977) sobre las identidades barriales en Buenos Aires y las de Mónica Lacarrieu (egresada de CA-UBA en 1980) sobre los conventillos del barrio porteño de la Boca. Asimismo, se abordaban las migraciones, tales como las estudiadas por Karasik junto al sociólogo Roberto Benencia (1941-2021, egresado de Sociología, Universidad Católica Argentina en 1977) respecto a la inmigración boliviana en Buenos Aires; o la de inmigrantes caboverdianos estudiados por Marta Maffia (egresada de la carrera de Antropología de la Universidad Nacional de La Plata, en adelante UNLP, en 1979). Las consecuencias del reasentamiento forzado de más de 20.000 personas en la ciudad de Posadas debido a la construcción del Proyecto Hidroeléctrico Yacyretá fueron estudiadas por equipos de la UNaM dirigidos por Leopoldo Bartolomé, donde se sumaría el antropólogo brasileño Gustavo Lins Ribeiro y en base a la cual escribiría su tesis doctoral en City University of New York en 1988, "Developing the Moonland: the Yacyretá Hydroelectric High Dam, Economic Expansion and Integration in Argentina". En junio de 1989, Guber iniciaba su trabajo de campo entre aquellos hombres que se autoadscribían como protagonistas directos del conflicto bélico entre la Argentina y Gran Bretaña por la soberanía en disputa de los archipiélagos australes de Malvinas, Georgias de1 Sur y Sandwich del Sur, entre el 2 de abril y el 14 de junio de 1982. Luego de una primera etapa de tres meses, retomaría el trabajo de campo entre 1991-1993 en Buenos Aires, Resistencia, Corrientes y Curuzú Cuatiá. Y en 1988 (casi simultáneamente a graduarme en CAUBA) iniciaba mi trabajo con profesionales y pacientes en el servicio de salud mental del Hospital "Gregorio Aráoz Alfaro", que al poco tiempo recuperaría su nombre original, "Evita", en Lanús.

En la segunda mitad de los años 1980 se desarrolló una experiencia que puede ser considerada una suerte de "escuela de trabajo de campo", liderada por Boivin ${ }^{24} \mathrm{y}$

\footnotetext{
24 Boivin, a quien habíamos visto integrando el equipo de Hermitte, había obtenido en 1982 una Maestría en Antropología Social de la London School of Economics and Political Science. Entre 1984-1990 se había desempeñado como Secretario Académico de la FFyL-UBA bajo la gestión del Decano Norberto Rodríguez Bustamante. Luego de un paso como Profesor Adjunto de Etnología General (la materia del plan de estudios vigente hasta 1985, cuyo Profesor Titular era, como ya señalé, Cordeu) en 1984, Boivin obtendría por concurso el cargo de Profesor Asociado de la materia "Antropología Sistemática I (Organización Social y Política)". En 1990 Boivin conformó una nueva cátedra, diferente a la entonces existente que presidía Neufeld, a la que se sumaría un grupo de jóvenes en calidad de auxiliares docentes. Fernando Balbi, que había cursado con él un seminario poco tiempo antes, cuenta que hacia el segundo semestre de 1989 Boivin le propuso integrarse a la materia que empezaría a dictar al año siguiente en calidad de auxiliar docente y, a tal fin, le pidió que leyese etnografías de Malinowski, Evans Pritchard, Leach y Godelier, para definir cuáles podían ser utilizadas en los trabajos prácticos.
} 
Rosato. En 1986 Ratier y Boivin encabezaron el "Programa de formación de jóvenes investigadores"; esto permitió incorporar alumnos con el propósito de estudiar o bien las cooperativas de pescadores del río Paraná en la provincia de Entre Ríos, bajo la dirección de Boivin o la formación de fábricas con villa obrera en la ciudad de Olavarría, bajo la dirección de Ratier donde, como señalé, trabajó Neiburg (Boivin, Rosato y Balbi, 2008: 11-12). Con el paso del tiempo, el grupo se fue reduciendo, ya que algunos se fueron a estudiar a Brasil (tema que trataré en el siguiente acápite) y otros, simplemente, decidieron seguir otros caminos. ${ }^{25}$ Boivin, Rosato y Sofía Tiscornia (aunque por breve tiempo) encabezaron el equipo. El proyecto tenía como objetivo estudiar etnográficamente la organización y funcionamiento de varias cooperativas de industrialización y comercialización de pescado en diferentes localidades de la zona del Paraná Medio, principalmente en el Departamento de Victoria. El proyecto se prolongó hasta 1991, pasando a tener cada vez más importancia el estudio de la relación entre esas cooperativas y las políticas estatales sobre la organización de la actividad pesquera. En tanto experiencia colectiva, varios jóvenes antropólogos pudieron desarrollar sus propios temas de investigación en conexión con el proyecto global (Balbi, Gaztañaga y Ferrero, 2017: 1617). El equipo desarrolló un estilo de trabajo de campo cooperativo, donde cada miembro compartía sus notas de campo con el resto, algo poco común en general. Esto posibilitaba la discusión colectiva que también conducía a análisis e interpretaciones consensuadas por el equipo (Boivin, Rosato y Balbi, 2008: 11).

Por supuesto, estos investigadores e investigadoras tenían mayores o menores diferencias respecto a los enfoques de la investigación, los modos concretos de practicar el trabajo de campo y la exposición de sus resultados, cuestión que demandaría una exploración mucho más exhaustiva, lo que excede con creces los objetivos que me planteo aquí. Pero esta lista parcial y heterogénea resulta útil para comprender mejor el panorama que ofrecía la antropología argentina en los años 1980 e inicios de los 1990 en relación a la investigación empírica. Como podemos ver, todas las experiencias mencionadas mostraban el lugar central que el trabajo de campo tenía en su práctica de investigación, más allá de las diferencias de estilos y de perspectivas teóricas. Esto contrastaba con las resistencias de aquellos estudiantes de la CA-UBA de los años 1990 a la hora de realizar sus prácticas de investigación o de analizar lecturas como Los argonautas del Pacífico Occidental, Los Nuer o Adolescencia, sexo y cultura en Samoa. Como también señalé, la postura refractaria al trabajo de campo y el enfoque etnográfico era sostenida por algunos profesores tanto en Buenos

25 Inicialmente, integraban el equipo de trabajo, además: Fernando Balbi, Gabriela Scotto, Carlos Kuz, Cecilia Ayerdi, Claudia Guebel, Laura Vugman (quien estaría por solo unos meses), Axel Lazzari, Jorge Gancedo, Gisela Fornassero (quien permaneció por un año aproximadamente) y María Laura Fruniz (quien continuó por poco menos de dos años).
Aires como otros centros académicos. Esto no podía sorprender, en la medida que la manera predominante de enseñar antropología era a través de la crítica, sea epistemológica o político-ideológica. ${ }^{26}$ Desde otro lugar, también contribuía con esta visión la enseñanza de la historia de la disciplina como una sucesión de teorías a las que podía demolerse fácilmente a través de la crítica, sin considerar problemas, estudios empíricos y contextos históricos. Sin embargo, en el curso de la década de 1990 la legitimidad de los desarrollos locales y las condiciones para la consolidación de una nueva matriz disciplinar recibirán una ayuda decisiva, proveniente de la antropología brasileña.

\section{La influencia de la antropología brasileña}

A partir de la década de 1990 la antropología argentina empezó paulatinamente a interactuar con mayor vigor con la antropología brasileña. En rigor de verdad, ya existían vínculos con dicha academia desde 1970, puesto que muchos antropólogos argentinos (en algunos casos, escapando del terrorismo de estado) se radicaron en Brasil y llevaron a cabo allí sus estudios e, incluso, sus carreras como profesores e investigadores. Entre ellos, el ya mencionado Ratier; Beatriz María Alasia de Heredia (graduada de la Universidad Nacional de Córdoba, en adelante UNC), quien se doctoró y fue profesora en el PPGAS-UFRJ; Roberto Ringuelet y Martín Ibañez Novion (ambos provenientes de la UNLP) y Luis María Gatti, también graduado de la UNC (Isola, 2018: 72); Guillermo Raúl Ruben, profesor del Programa de Posgraduación en Antropologia Social de la Universidade Estadual de Campinas (UNICAMP); Rita Segato, profesora del Departamento de Antropología de la Universidad de Brasilia (UnB) entre 1985 y 2010; o, más tarde, el de Neiburg, que había realizado estudios de maestría en FLACSO-Argentina en 1988 y se doctoró en 1993 en el PPGAS-UFRJ, donde desarrolló luego su carrera académica. Algunos pocos de estos antropólogos volvieron a la Argentina para retomar sus carreras (como Ratier y Ringuelet); la mayoría continuó viviendo en Brasil, aunque visitaron frecuentemente el país, debido a sus lazos con instituciones, colegas y amigos argentinos.

Poco a poco, las visitas de antropólogos brasileños se tornaron más frecuentes. Como ya anticipé, Lins Ribeiro (a quien conocí en 1985, a través de Guber) mantuvo una estrecha relación con Leopoldo Bartolomé, que le posibilitó

\footnotetext{
26 Ese era el papel que cumplía el ya mencionado "Modelo Antropológico Clásico" de Menéndez; pero un espíritu similar podía apreciarse en la obstinada insistencia en la crítica al concepto de cultura sin tener en cuenta los matices existentes entre enfoques diferentes o el hecho de que, para la Escuela Británica, por ejemplo, ni siquiera fuera un concepto central. Este puede ser el caso de la obra de Rockwell, que contiene valiosos aportes para la etnografía escolar, pero que cae en la generalización cuando aborda críticamente lo que considera una versión "clásica" de la noción de cultura, perdiendo de ese modo rigurosidad en sus análisis. Véase, por ejemplo, Rockwell (1991).
} 
llevar adelante su estudio sobre los conflictos identitarios de los trabajadores extranjeros que conformaban el mercado de trabajo que participaba de la construcción de la represa hidroeléctrica argentino-paraguaya Yacyretá; entre 1979 y 1990 Bartolomé se desempeñó como Director de la Unidad de Reasentamiento Urbano para la Entidad Binacional Yacyretá-Apipé (Lins Ribeiro, 2011). Si bien desde los años 1980 varios eventos científicos de la antropología argentina contaron con la visita de antropólogos brasileños, esto fue haciéndose cada vez más frecuente a partir de la primera mitad de los años 1990. Y estas visitas no solo se restringieron a la participación en tales eventos, sino que además los visitantes comenzaron a dictar cursos de posgrado, algo que se tornó habitual en Buenos Aires y en Posadas, especialmente. Entre esos visitantes, cabe mencionar a Moacir Palmeira, Luis Fernando Dias Duarte (con quien cursé un excelente seminario en 1994 en la UBA), Claudia Fonseca, Ruben Oliven, Roberto Cardoso de Oliveira, Cornelia Eckert, Giralda Seyferth, Lygia Sigaud, Arno Vogel, José Sergio Leite Lopes, Afrânio Garcia, más los ya mencionados Lins Ribeiro, Heredia, Ruben y Segato. A ellos, es necesario agregar a Roberto Cardoso de Oliveira, Roberto Da Matta, Gilberto Velho y Otávio Velho, Eduardo Viveiros de Castro o João Pacheco de Oliveira, que se hicieron sumamente conocidos a través de la difusión de su producción.

La circulación académica no solo fue desde Brasil a la Argentina. Los antropólogos argentinos empezaron a asistir más asiduamente a los eventos científicos en tierras brasileñas, pasando a conformar sus cronogramas anuales usuales de circulación. Eventos como el de la Associação Brasileira de Antropologia (ABA), los congresos de la Associação Nacional de Pós-graduação e Pesquisa em Ciências Sociais (ANPOCS) y la Reunión de Antropología del Mercosur (RAM), en los que los antropólogos participaban junto a otros colegas de las restantes ciencias sociales, fueron fundamentales para introducir nuevas agendas de investigación y estilos de discusión entre los antropólogos argentinos. El antecedente de las RAM fueron las ABA-SUL, reuniones de la ABA que agrupaban a los estados del sur de Brasil. Dada su repercusión más allá de las fronteras brasileñas, desde 1995 estos encuentros se transformaron en la RAM mediante la incorporación de las instituciones de los países comprendidos en el acuerdo regional. Precisamente, un importante contingente de argentinos participó de la RAM llevada a cabo en Tramandaí (un municipio del estado de Rio Grande do Sul) en setiembre de 1995. En abril del año siguiente, se repitió la situación en la "XX Reuniao Brasileira de Antropologia. I conferencia: Relaçoes Étnicas e Raciais na América Latina e Caribe", efectuada en Salvador de Bahía. Dado que en los años 1990 la posibilidad de financiamiento para viajes a eventos científicos era bastante limitada en la Argentina, fueron las instituciones brasileñas las que brindaron en muchos casos apoyo para los viajes y la estadía de los argentinos.
Volviendo a los años 1980, poco tiempo después del II CAAS, el 29 de diciembre de 1987, la FFyL-UBA aprobó un Convenio de Cooperación con el Programa de Pós-Graduação em Antropologia- Museu NacionalUniversidade Federal do Rio de Janeiro (PPGAS-MNUFRJ), cuyo coordinador era Leite Lopes. El objetivo residía en acrecentar los intercambios científicos entre las dos instituciones, aunque de modo principal lo que se pretendía era que desde CA-UBA pudiesen seleccionarse candidatos para la Maestría en Antropología que se dictaba en el Museu Nacional. Merced a un sistema de becas vigentes entre 1988 y 1997, muchos jóvenes antropólogos pudieron acceder a ese programa de posgrado. Si bien la crisis económica brasileña de 19981999 impactó en las posibilidades de subvencionar a los estudiantes argentinos, la concurrencia de estos no menguó (Isola, 2018). Es más, otros programas de posgrado resultaron también atractivos, como el de la Universidade de Brasília, la Universidade Estadual de Campinas o la Universidade Federal do Rio Grande do Sul.

¿Qué consecuencias tuvo este fluido intercambio con la antropología brasileña para la argentina? A diferencia de esta última, que a mediados de los años 1980 debía recorrer un arduo camino de construcción institucional, la brasileña contaba con muchos centros académicos de prestigio, revistas con gran calidad, una tradición importante de investigación, numerosos profesores -muchos de ellos formados en las principales instituciones de antropología del mundo, antropologías con las que mantenía fuertes y dinámicos nexos desde hacía varios años (Grimson y Semán, 2006). ${ }^{27}$ Más allá de las obvias diferencias teóricas esperables en cualquier academia, existía un enorme consenso respecto a qué era pensar y trabajar como antropólogos, siendo los posgrados la vía principal de trasmisión de los conocimientos disciplinares y el oficio. Ese aprendizaje consistía en leer antropología y, fundamentalmente, monografías etnográficas, puesto que las teorías debían aprenderse no meramente como formalizaciones, sino en el modo en que daban lugar a determinadas preguntas y respuestas empíricas. A partir de allí, los estudiantes comprendían que su tarea se emparentaría con la de aquellos autores clásicos que llevaron a cabo trabajo de campo intensivo para luego proceder a escribir una tesis de carácter monográfico a la que, especialmente en los años 1990, se empezó a denominar etnografía.

Al mismo tiempo, quienes se graduaron en las universidades brasileñas y volvían al país contaban con una perspectiva disciplinar que los situaba en condiciones especiales para el diseño de modos diferentes de practicar y enseñar la antropología social. Así, podían unirse a aquellos que

27 El lugar de la antropología brasileña para dicha generación puede verse en Grimson, Lins Ribeiro y Semán (2004). Para el desarrollo anterior de la antropología brasileña desde la perspectiva de antropólogos brasileños, véase por ejemplo Lins Ribeiro (1987) y Correa (1993). 
poco antes se habían formado en posgrados de Estados Unidos y Europa en un mismo proyecto: crear un campo de formación de posgrado en la Argentina.

\section{El surgimiento de los posgrados en antropología social en la Argentina}

Cuando se formalizó el convenio entre la UBA y el PPGAS-MN-UFRJ, no existía un programa de posgrado en Antropología Social en la Argentina. Recién en 1995 se creó el Programa de Postgrado en Antropología Social de la UNaM y, como parte del mismo, una maestría. Con el liderazgo de Leopoldo Bartolomé, la maestría conformó su staff de profesores con el plantel base del departamento: Gorosito Kramer (Magister en Antropología Social por la Universidad de Brasilia), Roberto Abínzano (egresado de CA-UBA en 1975 y doctorado en Antropología y Etnología de América por la Universidad de Sevilla en 1985), Denis Baranger (egresado de Sociología, UBA, en 1973 y doctorado más tarde en Ciencias Sociales, UBA, 2003), Fernando Jaume (graduado en Antropología en UNR y doctorado en The University of Texas-Austin) y Gabriela Schiavoni (antropóloga egresada de la UNaM y doctorada en FFyL-UBA en 1992). A este grupo se sumaría Guber más Vogel, Palmeira, Ruben y Lins Ribeiro, entre otros, que fueron habitualmente profesores visitantes. La maestría fue cursada por una gran cantidad de alumnos de todo el país (principalmente de la UBA, muchos de ellos también integrantes del GTTCE del IDES), haciendo posible que modos de pensar y practicar la disciplina no tan conocidos en el mundo académico local encontrasen un público académico joven en un contexto mucho menos conflictivo que el que prevalecía en otros ámbitos del país. Sus primeros graduados fueron, en este orden, Fernando Balbi (graduado en CAUBA) y Alejandro Grimson (graduado en Ciencias de la Comunicación, UBA) en 1998; como muchos de quienes estudiaron en Misiones, luego realizaron sus doctorados en universidades brasileñas: Balbi en el PPGAS-MN-UFRJ (2004) ${ }^{28}$ y Grimson en la Universidad de Brasilia (2002). Más tarde, en el año 2000, se inauguraría en la UNaM el doctorado en Antropología Social, el mismo año que se inició la Maestría en Antropología en la Universidad Nacional de Córdoba.

En 2001 (cuando el país entraba en una de las más graves crisis socio-económicas de su historia) se creó una nueva Maestría en Antropología Social, mediante un acuerdo interinstitucional entre el IDES (donde funcionaba el CAS) y el Instituto de Altos Estudios Sociales de la Universidad Nacional de General San Martín (en adelante, IDAESUNSAM). Primera maestría creada en Buenos Aires, fue el resultado de un largo proceso de gestación que se inició desde la mitad de los años 1990 con numerosos encuentros liderados por Guber, de los que participaron

28 En el mismo programa y en el mismo período, también se doctoraron, entre otros: Gustavo Sorá (1998), Fernando Rabossi (2004), Gustavo Blázquez (2004), Jorge Pantaleón (2004), Rolando Silla (2005), Virginia Vecchioli (2006) y Laura Masson (2007). en diferentes momentos y modos varios antropólogos residentes en el país o en el exterior (entre estos últimos, especialmente, Archetti, Ruben y Heredia). Contó en su staff inicial con los coordinadores Guber y Pablo Semán (graduado en Sociología por la UBA en 1991 y doctorado en Antropologia Social por el PPGAS- UFRGS, Brasil, en 2000), más Boivin, Rosato, Wright (doctorado en antropología en Temple University en 1997), Briones (doctorada en antropología en la Universidad de TexasAustin en 1999), Santiago Álvarez (abogado por la Universidad Católica Argentina en 1987 y Magister y Doctor en Antropología Social por la London School of Economics and Political Science en 1993 y 1998, respectivamente), Elizabeth Jelin (graduada en socióloga por la UBA en 1962 y Doctora en Sociología por la Universidad de Texas-Austin en 1968) y María Julia Carozzi (graduada en Sociología, UBA y doctora en Antropología por la Universidad de California, Los Ángeles). Poco después nos incorporaríamos a la vez Grimson y yo, tras doctorarme en la Universidad de Utrecht, Países Bajos, en 2001. Desde el comienzo, la maestría se propuso llevar a cabo una formación centrada en la investigación empírica con enfoque etnográfico, la cual debía expresarse en las tesis escritas. La creación de la maestría no solo constituía un modo de plasmar el proyecto disciplinar de Guber, potenciado por quienes se habían formado en Brasil. También fue un ámbito donde confluyeron en buena medida las trayectorias y experiencias expuestas en las secciones precedentes, como la de Boivin. Incluso, Wright y Briones, aunque provenientes del campo etnológico, fueron siempre colegas próximos a Guber, en lo que respecta a la importancia del trabajo de campo y la etnografía en general. ${ }^{29} \mathrm{Si}$ bien el grupo de antropólogos, con sus diferencias, venía transmitiendo desde hacía tiempo en sus clases en CA-UBA y publicaciones un enfoque disciplinar donde lo etnográfico tenía un lugar esencial, fue en la maestría donde el mismo pudo cristalizarse en un proyecto institucional, sustentado en una definición de lo que debía ser la antropología.

Con el nuevo siglo, la creación de posgrados en todas las ramas del conocimiento se intensificó; los nuevos posgrados en antropología fueron parte de ese proceso: FLACSO inauguró una diplomatura en Antropología Social y Política en 2004, bajo la dirección de Alejandro Isla y la Maestría en Antropología Social en 2006, el mismo año en que se crearon la Maestría en Antropología Social de la UBA y el Doctorado en Antropología Social de la UNSAM, bajo la dirección de Claudia Fonseca (profesora en el Programa de Pós-Graduação em Antropologia Social, Universidade Federal do Rio Grande do Sul) y la co-dirección de Grimson (quien había dejado el IDES y su maestría años antes). ${ }^{30}$ Este proceso confluyó con un

29 Al respecto, véase Guber (2018).

30 Para confirmar aún más los estrechos vínculos con la antropología brasileña y particularmente del IDAES, además de Fonseca, fueron profesores del doctorado: João Pacheco, Luis Fernando Dias Duarte, Neiburg, Fernando Rabossi, Marina Vanzolini, Adriana Viana y Maria Elvira Dias Benítez (PPGAS-MN-UFRJ); Fabiola Rohden, Elizabeth Lucas, 
incremento paulatino del financiamiento estatal en la educación universitaria y en el área de ciencia y tecnología, que se tradujo especialmente en el incremento de las becas de estudios doctorales y en los ingresos a la carrera de investigador científico del CONICET. La ampliación de las becas de formación doctoral del CONICET nutrió los posgrados, que a su vez lograron obtener durante un tiempo recursos financieros para solventar la matrícula de una buena parte de los estudiantes. ${ }^{31}$

Es cierto que la creación de posgrados (maestrías y doctorados) en antropología social en la Argentina, hoy afianzados (pese a las enormes dificultades de financiamiento) no puede ser visto como la expresión de una única perspectiva disciplinar. Algunos explicitan en sus objetivos una orientación cimentada en lo etnográfico, mientras que otros evitan la referencia a dicho término. No obstante, basta detenerse en las características de los proyectos de investigación doctoral y las tesis resultantes, así como en la modalidad de trabajo de los profesores de aquellos posgrados en los que lo etnográfico no aparece de manera manifiesta entre sus objetivos programáticos, para advertir que, sin caer en una desmedida y, por consiguiente, errónea visión de una disciplina homogénea, lo etnográfico ha terminado imponiéndose en una gran parte de los practicantes de lo que hoy llamamos el campo de la antropología social en el país.

\section{Conclusiones}

Una versión bastante difundida entre los antropólogos argentinos es que la antropología social, en su forma actual, es un producto de la democracia, recuperada en 1983 (Ratier y Ringuelet, 1997). Por supuesto, las condiciones generadas a partir del retorno democrático hicieron posible un desarrollo que la aproximó a otras academias donde la disciplina estaba largamente consolidada. Sin embargo, esta idea de una ruptura drástica con el pasado antes de 1983 presenta algunas dificultades, en la medida que subsume rápidamente la historia disciplinar a los modos de periodizar el proceso político nacional (Guber y Visacovsky, 1997-1998). Por otra parte, como lo ha mostrado Guber (2001), "antropología social" en la Argentina no remite meramente a una etiqueta disciplinaria, sino que constituye una categoría identitaria que es, a la vez, académica y política. Esto permite comprender muchas de las lecturas sobre el pasado disciplinar como epifenómeno del pasado político; ciertamente, ese tiempo denominado "presente" iniciado, justamente, tras la recuperación democrática, ha recibido escasa atención, pese a que lleva nada más ni nada menos que casi cuarenta años: un presente que es efecto de una discontinuidad con un pasado ominoso.

Carlos Steil, Emerson Giumbelli, Bernardo Lewgoy, Arlei Sander Damo (PPGAS- UFRGS); Omar Ribeiro Thomasz, John Monteiro, (UNICAMP) y Gustavo Lins Ribeiro (UnB), entre otros.

31 Sobre el desarrollo del CONICET en el período 2003-2015, véase Alasino (2019 y 2020).
En lugar de esta versión de la historia disciplinar, lo que encontramos es que tras la recuperación democrática se produjeron desarrollos locales que tenían su base en formas de pensar y practicar la antropología en los años 1960 y 1970, los cuales, a su vez, debían su perspectiva antropológica a las formaciones recibidas en Estados Unidos, Gran Bretaña o Francia (Guber y Visacovsky, 1999 y 2000). Tal fue el caso de Hermitte, quien desde su retorno a la Argentina en la década de 1960 cumplió un rol principal para el desarrollo de una antropología social fundada en el trabajo de campo intensivo. A partir de 1984, desde la cátedra de MYTIC, Hermitte llevó este enfoque a la CA-UBA; para ello, contaba con varios antropólogos que podían contribuir con ese proyecto, como Herrán, Guber y Boivin. Sin embargo, en ese espacio académico de la carrera Hermitte se encontraría con colegas que practicaban otros estilos de trabajo de campo o que no necesariamente compartían su idea acerca de la antropología. Así como un grupo se congregó en torno a Hermitte, otros lo hicieron bajo otros liderazgos que representaban concepciones disciplinares bastante diferentes. Al menos en el caso de CA-UBA -y quizá para todos los centros académicos de enseñanza e investigación antropológica del país-, los años que siguieron a la recuperación democrática se caracterizaron por la conformación de grupos que se especializaron tempranamente en torno a ciertos temas (como lo urbano, la educación o la salud), respondiendo a determinadas genealogías locales a la vez que rechazando otras. $^{32}$ Como señalamos antes, estas adhesiones y rechazos comprendían tanto una perspectiva sobre el pasado político nacional como una concepción de la práctica antropológica, a la cual podían ver, según los casos, con mayor o menor autonomía respecto a lo político. Y esto tenía consecuencias, obviamente, sobre qué implicaba "hacer antropología social". ${ }^{33}$

\footnotetext{
32 Me refiero a la conformación de grupos enfocados en temáticas específicas, cuyos integrantes se asumieron como discípulos de determinadas figuras que, a su vez, eran vistas como diferentes y opuestas a otras cabezas de grupos en aspectos que iban desde las concepciones propiamente disciplinares hasta el posicionamiento político. Si apelamos a nociones clásicas como linaje (en tanto un grupo de descendencia cuyos miembros son reclutados de modo automático por ser descendientes de un antepasado común), podríamos plantear la existencia de grupos diversos desde los años 1980 (y aun posteriormente), que se asumieron descendientes de Eduardo Menéndez (como el grupo de antropología médica de la UBA), Hermitte (como el grupo de antropología urbana de la UBA que encabezó Herrán y, posteriormente, el CAS en el IDES liderado por Guber), Leopoldo Bartolomé (como el programa de antropología en la UNaM), Edgardo Cordeu (como el grupo de estudios etnológicos en la UBA), por mencionar solo algunos. Véase al respecto Hidalgo (19971998) y los comentarios al mismo de Podgorny (1997-1998). También, desde una perspectiva diferente, Guber (2006).

33 A diferencia de lo que había ocurrido antes de 1984, los cursos de antropología social incluyeron de modo masivo lecturas de obras clásicas, aprovechando que buena parte de ellas había sido editada en español (tal era el caso de los libros de Claude Lévi-Strauss). La editorial española Anagrama ofrecía a través de su Biblioteca de Antropología obras de autores fundamentales, como Radcliffe-Brown, Evans-Pritchard, Leach, Dumont o Godelier, entre otros. La dificultad residía en comprender cómo estos textos podían contribuir a la enseñanza de la antropología social. Ahí se produjeron las mayores
} 
En este contexto, Guber continuó el proyecto de Hermitte, pero lo amplió, convirtiéndolo en un programa disciplinar que quedó expuesto más claramente con la publicación de El Salvaje Metropolitano, pero también por su papel desde la cátedra de MYTIC en la CA-UBA, donde sostuvo su posición frente a la propuesta más epistemológica de Batallán. A la vez, ambas debieron afrontar la manifiesta hostilidad de parte de algunos estudiantes y profesores respecto al trabajo de campo y la tradición antropológica. ${ }^{34}$ Si bien Guber dejaría CA-UBA en 1996, ella generó diferentes alternativas para la difusión de su programa disciplinar, principalmente a través de la refundación del CAS, la organización del GTTCE y las JEMC (todos con sede en el IDES), su participación en la novel Maestría en Antropología Social en la UNaM y su estudio de los estilos de investigación de Hermitte, Archetti, Vessuri, Bilbao y Bartolomé en los años 1960 y 1970 que (intencionalmente o no), hacían posible postular una genealogía local diferente para quienes sostenían una perspectiva disciplinaria cuyo corazón fuese lo etnográfico. Como señalé, Guber compartía con otros colegas las mismas ideas acerca de la importancia del trabajo de campo y la producción etnográfica. Pero ella daría un paso más: imaginó un proyecto disciplinar. Ella se planteó la necesidad de una reorientación de la antropología social en la Argentina, cuyo eje debía ser el trabajo de campo tal como este era entendido en la tradición disciplinar anglosajona, pero también en gran medida francesa y brasileña (como veremos enseguida). A esto, Guber le añadiría la importancia de concebir el trabajo de campo como método en íntima asociación con un enfoque, cuya meta fuese aprehender el punto de vista nativo y con un modo de describir la actividad humana en una sociedad (esto es, como producto textual), cuyo propósito fuese la representación, interpretación o traducción de una cultura (o aspectos de esta) a una audiencia no familiar. Guber definiría esta triple conexión como etnografía (Guber, 2001b: 12). En buena medida, sus investigaciones sobre la historia y la conformación del campo de la antropología en la Argentina, con especial interés en la antropología social, deberían verse como parte de su preocupación por el desarrollo y afianzamiento de la etnografía, como un modo de practicar la disciplina.

discrepancias: mientras algunos sostuvieron la relevancia de estas lecturas en estrecha conexión con las investigaciones etnográficas que las sustentaron, otros promovieron una perspectiva fuertemente crítica, ya sea porque habrían expresado una ideología colonialista que prevaleció en la disciplina desde sus orígenes y/o por presentar problemas epistemológicos insalvables.

34 Es importante recordar que la enseñanza de métodos de investigación no es algo habitual en las academias tradicionales en antropología social. Más bien, la enseñanza de la etnografía como trabajo de campo y enfoque analítico ha estado más ligada a los intereses sociológicos. Sin embargo, la existencia de cursos curriculares en metodología de la investigación en antropología social y los mismos esfuerzos de Guber y otros por su enseñanza deben verse en relación con la situación de la antropología en la Argentina, con la necesidad de desarrollar un modo de pensar y practicar la disciplina que hasta los primeros años del nuevo siglo seguía siendo muy acotada.
Quienes habían estudiado en academias antropológicas estadounidenses o europeas disponían de modelos o ejemplos a seguir, los cuales les ayudarían a encarar las investigaciones como la resolución de rompecabezas o acertijos (Kuhn, 1985). Estos modelos provenían, muy especialmente, de la lectura de monografías etnográficas, basadas en trabajo de campo intensivo. Como vimos, Guber insistió desde un primer momento en su importancia crucial, tanto en la enseñanza como en la investigación, pero no necesariamente en consonancia con el programa propuesto por quienes desde los años 1980 en los Estados Unidos sostenían la primacía del análisis textual. Por el contrario, Guber entendía que una buena monografía o un artículo etnográfico podía ser evaluado en términos de los argumentos y las evidencias aportadas, tal como lo planteaba David Jacobson (1991). Así como en el pasado lo habían hecho (o no) quienes eran considerados modelos o ejemplares para la práctica científica, así lo deberían hacer (o no) quienes aprendían a través de ellos.

Desde la segunda mitad de los años 1980 se fueron conformando grupos liderados por un profesor (o más) con mayor trayectoria y experiencia, junto a jóvenes estudiantes o graduados, tales como el GTTCE creado y dirigido por Guber a mediados de los años 1990, o el que forjó y lideró Boivin. Estas experiencias (como las de otros grupos) acompañaron la paulatina transformación del campo disciplinar, en la medida que el trabajo de campo se convertía en el motor de la investigación y se tornaba una práctica aceptada, necesaria y ponderada, a punto tal que emergía como una posible nueva identidad: la del trabajador de campo o el etnógrafo. En consecuencia, sea a través del aprendizaje del trabajo de campo mediante una práctica colectiva, sea su discusión epistemológica y metodológica, fue gestándose una nueva generación de antropólogos, con una concepción disciplinar más homogénea y próxima a otras antropologías del mundo.

Pero estos desarrollos locales sustentados en formaciones en Estados Unidos o Europa fueron expandidos y fortalecidos cuando la antropología brasileña influyó decisivamente en el campo disciplinar argentino en el curso de los años 1990. Por entonces, muchos jóvenes antropólogos (como los que se habían formado en grupos como los que lideraban Guber y Boivin) llevaron a cabo sus estudios de posgrado en universidades brasileñas. Además, al participar de eventos científicos de la antropología brasileña, los jóvenes antropólogos argentinos (y no tan jóvenes) incorporaron reglas de juego académico: qué tipo de escritos y discusiones eran académicamente aceptables y cuáles no en términos propiamente antropológicos; cómo y para qué leer las teorías y las etnografías antropológicas; cómo escribir; cómo argumentar. La antropología brasileña poseía prestigio, contaba con una producción de gran magnitud y relevancia, sus instituciones eran muy vitales y disponía 
de recursos financieros para la enseñanza, la investigación y la difusión científica. Por esto, la antropología brasileña podía conferir total legitimidad al modelo de práctica disciplinar centrado en una experiencia de trabajo de campo intensiva y a la producción de monografías etnográficas. La antropología brasileña, en definitiva, planteaba una manera de pensar y practicar la disciplina donde el trabajo de campo y la experiencia etnográfica eran centrales. La formación de posgrado de una nueva generación de antropólogos argentinos siguió dependiendo de una academia extranjera, aunque próxima, con la posibilidad de interactuar más fluidamente.

Pero fueron los posgrados los que contribuyeron decididamente en la consolidación de una nueva matriz disciplinar, porque permitieron crear nuevas alianzas y nuevos proyectos académicos y científicos por fuera de las carreras de grado existentes. Posgrados como la Maestría en Antropología Social del IDES-IDAES/UNSAM ofrecieron la posibilidad de materializar los proyectos disciplinares a través de su institucionalización. Y, fundamentalmente, reorientar la formación de los jóvenes antropólogos, donde lo etnográfico (trabajo de campo y escritura de tesis desde un tipo específico de enfoque) constituyeron el eje vertebrador. Tras la crisis socioeconómica y política de la Argentina de inicios del presente siglo, estos posgrados prosperaron merced al financiamiento que suministraron organismos del Estado como el CONICET durante el período 2003-2015. El creciente número de tesis de maestría y doctorado, muchas de ellas publicadas en editoriales ${ }^{35}$ como Antropofagia (dirigida por Santiago Álvarez), ${ }^{36}$ la aparición con el paso del tiempo de nuevas

35 Desde inicios del nuevo siglo, vieron la luz varios libros etnográficos, la mayor parte basados en tesis doctorales, que sentaron las bases de lo que sería una nueva corriente de producción etnográfica por parte de antropólogos argentinos. Entre esas obras, cabe mencionar ¿Por qué Malvinas? De la causa nacional. a la guerra absurda, de Rosana Guber (2001); El Lanús: memoria y política en la construcción de una tradición psiquiátrica y psicoanalítica argentina, de Sergio Visacovsky (2002); Leviatán y sus lobos: violencia y poder en una comunidad de los Andes colombianos, de Santiago Álvarez (2004); Buenos vecinos, malos políticos: moralidad y política en el Gran Buenos Aires, de Sabina Frederic (2004); De chicos a veteranos: memorias argentinas de la guerra de Malvinas, de Guber (2004); De leales, desleales y traidores: valor moral y concepción de política en el peronismo, de Fernando Alberto Balbi (2007).

36 Durante el período 2004-2007 la editorial Antropofagia publicó las siguientes tesis de maestría: La virgen prestamista. La fiesta de la Virgen de Urkupiña en el boliviano Gran Córdoba, de Marta Giorgis; La política en femenino. Género y poder en la provincia de Buenos Aires, de Laura Masson; Las niñas Gutierrez y la mina Alumbrera, de Andrea Mastrangelo; Aprender a ser chilenos. Identidad, trabajo y residencia de migrantes en el Alto valle de Rio Negro, de Verónica Trpin (todas en 2004); La mano que acaricia la pobreza: etnografía del voluntariado católico, de Laura Zapata; Entre la carta y el formulario: política y técnica en el desarrollo social, de Jorge Pantaleón; Locas, chongos y gays: sociabilidad homosexual masculina durante la década de 1990, de Horacio Sívori (todas de 2005); Bolivianos, paraguayos y argentinos en la obra. Identidades étnico-nacionales entre los trabajadores de la construcción, de Patricia Beatriz Vargas; De boca en boca. El chisme en la trama social de la pobreza, de Patricia Fasano; Para hombre ya estoy yo: masculinidades y socialización lésbica en un bar del centro de Río de Janeiro, de Andrea Lacombe; revistas, así como la publicación cada vez más frecuente de trabajos de antropólogos argentinos en revistas internacionales, la diversificación temática, la presencia de antropólogos como expertos en los medios de comunicación y, aún más, desempeñándose en la función pública, todo esto conformó un panorama que expresó no solo el inmenso impulso de la antropología desde los años 1990 hasta ahora, sino fundamentalmente un desarrollo orientado por una matriz disciplinar cuyo núcleo ha sido lo etnográfico.

Por supuesto, no estoy afirmando que hayan desaparecido otras formas de pensar y practicar la antropología (es decir, llevadas a cabo en nombre de la antropología); tampoco sostengo que todos quienes realicen trabajo de campo lo hagan del mismo modo, que los textos etnográficos sigan reglas de exposición similares o que todos quienes invoquen la noción de "etnografía" estén confiriéndole el mismo sentido. Pero, aun así, lo novedoso reside en un consenso disciplinar basado en la idea que conocer antropológicamente supone practicar etnografía. Un consenso que llevó más de cuarenta años y demandó el entrenamiento de antropólogos locales en academias extranjeras, una legitimidad que brindó una academia latinoamericana prestigiosa como la brasileña y la conformación y consolidación de grupos locales que cristalizaron sus proyectos disciplinares al institucionalizarlos en posgrados que, en varios casos, lograron romper el monopolio de las definiciones de ciencia legítima que poseían las carreras de grado. No obstante, lejos de ver en esto una teleología virtuosa, los años próximos deberían permitirnos la interrogación de este consenso y no solo a través de las reflexiones promovidas desde, sobre todo, las antropologías de Estados Unidos, Gran Bretaña y Francia, sino también a partir de las condiciones de producción científica, las experiencias académicas y políticas y la historia, en definitiva, de quienes practican la antropología en la Argentina.

\section{Agradecimientos}

Mi agradecimiento a Rosana Guber, Fernando Balbi, Gabriel Noel, Mariano Perelman, Luis Ferreira, Ariel Gravano y Mónica Lacarrieu por sus lecturas y diferentes aportes en la elaboración de este texto.

\section{Bibliografía}

Abduca, R. (1995). El antropólogo como informante. El trabajo de campo, su práctica y su escritura. Publicar en Antropología y Ciencias Sociales, 4(5), 47-70.

\section{Alasino, C. M. (2019). Recursos, producción y}

Cruzando la Sarmiento. Una etnografía sobre piqueteros en la trama social del sur del Gran Buenos Aires, de Julieta Quirós (todas de 2006); y Entiendo pero no hablo. El guaraní "acorrentinado" en una escuela rural: usos y significaciones, de Carolina Gandulfo (2007). 
productividad del CONICET. Debate Universitario, 7(13), 21-57.

Alasino, C. M. (2020). CONICET: una mirada al pasado reciente. Ciencia e Investigación, 70(1), 12-31.

Balbi, F. A. (2015). Retratistas de mariposas. Acerca del lugar subordinado de la comparación en la antropología social y cultural contemporánea. Revista del Museo de Antropología, 8(1), 171-186.

Balbi, F. A. (2020). La inversión de la teoría en la etnografía en antropología social. Revista del Museo de Antropología, 13(2), 203-214.

Balbi, F. A., Gaztañaga, J., y Ferrero, L. (2017). Introducción. Pensar la comparación para pensar comparativamente. En F. A. Balbi (Ed.), La comparación en Antropología Social: problemas y perspectivas (págs. 7-27). Buenos Aires: Antropofagia.

Batallán, G. (1995). Autor y Actores en Antropología: Tradición y ética en el trabajo de campo. Revista de la Academia (1), 97-106.

Batallán, G. y García, J. F. (1992). Antropología y Participación, contribución al debate metodológico. PUBLICAR-en Antropología y Ciencias Sociales (1), 79-93.

Boivin, M., Rosato, A., y Balbi, F. A. (2008). Introducción. Pesca comercial y asentamiento humano en el Departamento de Victoria, Entre Ríos, entre 1986 y 1995. En M. Boivin, A. Rosato, y F. A. Balbi (Edits.), Calando la vida. Ambiente y pesca artesanal en el Delta Entrerriano (págs. 7-26). Buenos Aires: Antropofagia.

Cardoso de Oliveira, R. (1988). Sobre o pensamento antropológico. Rio de Janeiro/ Brasília: Tempo Brasileiro ICNPq.

Cardoso de Oliveira, R. y Ruben, G. R. (Edits.) (1995). Estilos de antropologia Campinas: Editora da Unicamp.

Casabona, V. I. y Guber, R. (1985). Marginalidad e integración: una falsa disyuntiva. En L. Bartolomé (Ed.), Relocalizados: Antropología Social de las poblaciones desplazadas (págs. 145-164). Buenos Aires: IDES.

Correa, M. (1993). Breve esbozo de la antropología brasileña reciente (1960-1980). Alteridades, 3(6), 1316.

Da Col, G. y Graeber, D. (2011). Foreword: The return of ethnographic theory. HAU: Journal of Ethnographic Theory, 1(1), vi-xxxv.
Da Col, G. (2017). Two or three things I know about Ethnographic Theory. HAU: Journal of Ethnographic Theory, 7(1), 1-8.

Da Matta, R. (1978). O oficio de etnólogo ou como ter anthropological blues. En E. d. Nunes (Ed.), A aventura sociológica (págs. 23-35). Rio de Janeiro: Zahar.

Gordillo, G. (1996). Hermenéutica de la ilusión: la etnología fenomenológica del Marcelo Bórmida y su construcción de los indígenas del Gran Chaco. Cuadernos de Antropología Social (9), 135-171.

Gravano, A. (1995). La imaginación antropológica. Interpelaciones a la otredad construida y al método antropológico. Publicar en Antropología y Ciencias Sociales, 4(5), 71-91.

Griaule, M. (1957). El método de la etnografía. Buenos Aires: Nova.

Grimson, A. y Semán, P. (2006). Introducción. Antropología brasileña contemporánea. Contribuciones para un diálogo latinoamericano. Journal of the World Anthropology Network (2), 155-165.

Grimson, A., Lins Ribeiro, G. y Semán, P. (Edits.). (2004). La antropología brasileña contemporánea. Buenos Aires: Prometeo.

Guber, R. (1984). La construcción de la identidad étnica. Integración y diferenciación en los inmigrantes judíos ashkenazim en la Argentina. En Antropología Argentina 1984 (págs. 197-211). Buenos Aires: Editorial de Belgrano.

Guber, R. (1991). El salvaje metropolitano. Buenos Aires: Legasa.

Guber, R. (1992). Comentario a 'Antropología: Perspectivas para después de su muerte". de Carlos Reynoso. PUBLICAR-en Antropología y Ciencias Sociales (2), 95-98.

Guber, R. (1993-1994). La relación oculta. Realismo y reflexividad en dos etnografías. Relaciones de la Sociedad Argentina de Antropología, 19, 37-66.

Guber, R. (1995). Antropólogos nativos en la Argentina. Análisis reflexivo de un incidente de campo. Publicar en Antropología y Ciencias Sociales, 4(5), 25-46.

Guber, R. (1999). "“El Cabecita Negra” o las categorías de la investigación etnográfica en la Argentina. Revista de investigaciones folclóricas (14), 108-120.

Guber, R. (2001a). Antropologia social": uma categoria 
nativa de la diáspora antropológica argentina. Anuário Antropológico, 26(1), 169-189.

Guber, R. (2001b). La etnografía, método, campo y reflexividad. Bogotá: Norma.

Guber, R. (2002). An Argentine diaspora between revolution and nostalgia. Anthropology Today, 18(4), 8-13.

Guber, R. (2006). Linajes ocultos en los orígenes de la antropología social de Buenos Aires. Avá. Revista de antropología (8), 1-35.

Guber, R. (2007). Crisis de presencia, universidad y política en el nacimiento de la antropología social de Buenos Aires, Argentina. Revista colombiana de antropología (43), 263-298.

Guber, R. (2008). Antropólogos-ciudadanos (y comprometidos) en la Argentina. Las dos caras de la "antropología social" en 1960-70. Journal of the World Anthropology Network, 3, 67-109.

Guber, R. (2010a). Otras antropologías y otras historias de la antropología argentina. Revista del Museo de Antropología (3), 169-170.

Guber, R. (2010b). El compromiso profético de los antropólogos sociales argentinos, 1960-1976. Avá. Revista de Antropología 16: 11-31.

Guber, R. (2017). Los comienzos en los confines: la noopción por la antropología social de Leopoldo J. Bartolomé y Carlos A. Herrán. Avá, Revista de Antropología, 2(25), 35-62.

Guber, R. (2018a). Experiencias etnográficas sudamericanas: ¿parte del problema o de la solución? Avá: Revista de Antropología, 32, 57-77.

Guber, R. (2018b). Hermitte, Esther (1921-90). En $\mathrm{H}$. Callan (Ed.), The International Encyclopedia of Anthropology (págs. 1-3). New York: JohnWiley y Sons, Ltd.

Guber, R. y Visacovsky, S. E. (1997-1998). Controversias filiales: la imposibilidad genealógica de la antropología social de Buenos Aires. Relaciones de la Sociedad Argentina de Antropología, 22-23, 25-53.

Guber, R. y Visacovsky, S. E. (1999). Imágenes etnográficas de la nación: La antropología social argentina de los tempranos años setenta. Série Antropologia. Universidade de Brasília, Departamento de Antropologia.

Guber, R. y Visacovsky, S. E. (2000). La antropología social en la Argentina de los' 60 y'70. nación, marginalidad crítica y el" otro" interno. Desarrollo Económico, 40(158), 289-316.

Guber, R. y Visacovsky, S. E. (2006). The Birth of Ciencias Antropológicas at the University of Buenos Aires, 1955-1965. Histories of Anthropology Annual, 2(1), 1-32.

Guebel, C. y Zuleta, M. I. (1995). "Yo hablaba y no me miraban a los ojos..." Reflexiones metodológicas acerca del trabajo de campo y la condición de género. Publicar en Antropología y Ciencias Sociales, 4(5), 93-101.

Hermitte, E. y Boivin, M. (1985). Erradicación de "“villas miseria" y las respuestas organizativas de sus pobladores. En L. Bartolomé (Ed.), Relocalizados: Antropología Social de las Poblaciones Desplazadas (págs. 117-144). Buenos Aires: IDES.

Hermitte, E. y Herrán, C. (1970). ¿Patronazgo o cooperativismo? Obstáculos a la modificación del sistema de interacción social en una comunidad del noroeste argentino. Revista Latinoamericana de Sociología, 2, 293-317.

Hermitte, E. y L. Bartolomé, L. comp. (1977). Procesos de articulación social. Buenos Aires: Amorrortu editores.

Hermitte, Esther, Alejandro Raúl Isla, and Nicolás Iñigo Carrera (1996). Estudio sobre la situación de los aborígenes de la Provincia del Chaco, y políticas para su integración a la sociedad nacional. Posadas: Editorial Universitaria.

Hermitte, E., Boivin, M., Casabona, V. I., Guber, R. y Tiscornia, S. (1983). Análisis de dos comunidades del Gran Buenos Aires: impactos externos y autogestión. Buenos Aires: FLACSO. Programa Argentina.

Hidalgo, C. (1997-1998). Antropología del mundo contemporáneo. Relaciones de la Sociedad Argentina de Antropología, 22-23, 71-81.

Howell, S. (2017). Two or three things I love about ethnography. HAU: Journal of Ethnographic Theory, 7(1), 15-20.

Ingold, T. (2008). Anthropology is not ethnography. Proceedings of the British Academy (154), 69-92.

Ingold, T. (2014). That's enough about ethnography! HAU: Journal of Ethnographic Theory, 4(1), 383-395.

Ingold, T. (2017). Anthropology contra ethnography. HAU: Journal of Ethnographic Theory, 7(1), 21-26. 
Isola, N. J. (2018). Argentinos à brasileira. A circulação de antropólogos argentinos pelo museu nacional (PPGASMN/UFRJ). Mana, 24(2), 68-108.

Jacobson, D. (1991). Reading ethnography. New York: Suny Press.

Kuhn, T. (1985). La estructura de las revoluciones científicas. México: Fondo de Cultura Económica.

Lebedinsky, V. (1994). De pasiones y muertes. Reflexiones sobre la antropología. PUBLICAR-En Antropología y Ciencias Sociales (4), 101-109.

Lins Ribeiro, G. (1987). Caminos de la antropología en Brasil. Contribución para una interpretación cultural mutua. Runa (17), 65-82.

Lins Ribeiro, G. (2011). Antropología de la globalización. Circulación de personas, mercancías e informaciones. Cuaderno Urbano. Espacio, cultura, sociedad, 10(10), 159-186.

Miller, D. (2017). Anthropology is the discipline but the goal is ethnography. HAU: Journal of Ethnographic Theory, 7(1), 27-31.

Perelman, M. (2015). On (social) Anthropology in Argentina Today. American Anthropologist, 117(3), 565-586.

Perelman, M. (2016). Notas sobre la institucionalización académica de la antropología social hoy. Quehaceres, 3, 121-136.

Podgorny, I. (1997-1998). Comentario. Relaciones de la Sociedad Argentina de Antropología, 22-23, 87-90.

Ratier, H. (2010). La antropología social argentina: su desarrollo. PUBLICAR-En Antropología y Ciencias Sociales, 8(9), 17-46.

Ratier, H. y Ringuelet, R. R. (1997). La antropología social en la Argentina: un producto de la democracia. Horizontes antropológicos, 3(7), 10-23.

Reynoso, C. (Ed.). (1991). El surgimiento de la antropología posmoderna. México: Gedisa.

Reynoso, C. (1992). Antropología: Perspectivas para después de su muerte. PUBLICAR-en Antropología y Ciencias Sociales (1), 15-30.

Reynoso, C. (1992). Polémicas de ultratumba. PUBLICARen Antropología y Ciencias Sociales (2), 99-106.

Reynoso, C. (2011). A propósito de la muerte de la antropología: reporte de una autopsia. PUBLICAR-en Antropología y Ciencias Sociales (10), 11-46.

Rockwell, E. (1991). Etnografía y Teoría de la Investigación Educativa. En G. Mariño (Edit.), Investigación Etnográfica Aplicada a la Educación (págs. 4-18). Bogotá: Dimensión Educativa.

Silla, R. (2012). Raza, raciología y racismo en la obra de Marcelo Bórmida. Revista del Museo de Antropología, 5(1), 65-76.

Silla, R. (2019). Barbarie y alocronía en el proyecto etnológico de Marcelo Bórmida. Revista del Museo de Antropología, 12(2), 101-112.

Vessuri, H. (1973a). La observación participante en Tucumán 1972. Revista Paraguaya de Sociología, 27(59), 59-76.

Vessuri, H. (1973b). Técnicas de recolección de datos en la antropología social. Etnía, 18(75), 3-20.

Visacovsky, S. E. (1992). Comentario a 'Antropología: Perspectivas para después de su muerte", de Carlos Reynoso. PUBLICAR-en Antropología y Ciencias Sociales (2), 91-94.

Visacovsky, S. E. (1993-1994). Diálogo, interpretación y autoritarismo en la etnografía contemporánea. Relaciones de la Sociedad Argentina de Antropología, 19, 7-35.

Visacovsky, S. E. (1995). La invención de la etnografía. Publicar en Antropología y Ciencias Sociales, 4(5), 7-24.

Visacovsky, S. E. (2002). Santiago Bilbao y el Folklore como pasaje a una antropología de la gestión estatal. En S. E. Visacovsky y R. Guber (Edits.), Historias y estilos de trabajo de campo en la Argentina (págs. 317-346). Buenos Aires: Antropofagia.

Visacovsky, S. E. (2006). In Memoriam. Folclore y modernización disciplinaria en la obra de Santiago Bilbao. Revista de Investigaciones Folclóricas 21: 169177.

Visacovsky, S. E. (2017). Etnografía y antropología en Argentina: propuestas para la reconstrucción de un programa de investigación de lo universal. Antípoda. Revista de Antropología y Arqueología, 27, 65-91.

Visacovsky, S. E. y Guber, R. (Edits.). (2002). Historias y estilos de trabajo de campo en la Argentina. Buenos Aires: Antropofagia. 
Visacovsky, S. E., Guber, R., y Gurevich, E. (1997). Modernidad y tradición en el origen de la carrera de
Ciencias Antropológicas de la Universidad de Buenos Aires. Redes, 4(10), 213-257. 